\title{
Microstructure and Mechanical Properties of Al-Co-Cr-Fe-Ni Base High Entropy Alloys Obtained Using Powder Metallurgy
}

\author{
Łukasz Rogal ${ }^{1}$ - Zbigniew Szklarz ${ }^{2}$. Piotr Bobrowski ${ }^{1}$ - Damian Kalita ${ }^{1}$ - Grzegorz Garzeł ${ }^{1}$ - Anna Tarasek ${ }^{1}$. \\ Marcin Kot ${ }^{3} \cdot$ Maciej Szlezynger ${ }^{1}$
}

Received: 2 February 2018 / Accepted: 21 December 2018 / Published online: 13 January 2019

(c) The Author(s) 2019

\begin{abstract}
Four different compositions of high entropy alloys based on $\mathrm{Al}-\mathrm{Co}-\mathrm{Cr}-\mathrm{Fe}$ and $\mathrm{Al}-\mathrm{Co}-\mathrm{Cr}-\mathrm{Fe}-\mathrm{Ni}$ systems were prepared using mechanical alloying and consolidation by spark plasma sintering. The chemical compositions of the studied alloys were experimentally selected to obtain a BCC solid solution and mixtures of BCC with FCC. The microstructure of the $\mathrm{A} 125 \mathrm{Co} 25 \mathrm{Cr} 25 \mathrm{Fe} 25$ (all in at\%) high entropy alloy consisted of a matrix with a high concentration of $\mathrm{Al}, \mathrm{Co}$ and $\mathrm{Fe}$, in which spherical grains (50-200 nm) enriched in $\mathrm{Cr}$ were embedded. Both the matrix and grains had body centered cubic structures. The addition of nickel to a four-element system led to the formation of a multiphase composition. The microstructure of the Al20Co20Cr20Fe20Ni20, Al10Co30Cr20Fe35Ni5 and Al15Co30Cr15Fe40Ni5 HEAs consisted of fine grains measuring 50-500 nm composed of: AlNi-B2, BCC phase, FCC or BCC solid solutions and $\sigma$-sigma phase, respectively. The complex structure of the studied samples resulted in changeable mechanical properties. The highest compression strength of $3920 \mathrm{MPa}$ was accompanied by an increased yield strength of $3500 \mathrm{MPa}$, and a low strain of $0.7 \%$, for the Al25Co25Cr25Fe25 alloy. The addition of Ni led to the formation of plastic FCC phases responsible for a decrease in strength with increases in ductility, which, in the new non-equiatomic A110Co30Cr20Fe35Ni5 high entropy alloy reached 6.3\% at a yield strength of $1890 \mathrm{MPa}$ and compression strength of $2230 \mathrm{MPa}$. The conducted abrasion studies revealed that non-equilibrium high entropy alloys have the highest abrasion resistance.
\end{abstract}

Keywords High entropy alloy $\cdot$ TEM studies $\cdot$ Mechanical properties $\cdot$ Mechanical alloying

\section{Introduction}

High entropy alloys (HEAs) belong to newly developed multicomponent alloys with superior mechanical properties in a wide temperature range, which can constitute an alternative to traditional alloys based on aluminum, titanium or steel [1]. The early research into HEAs explored mainly single

Łukasz Rogal

1.rogal@imim.pl

1 Institute of Metallurgy and Materials Science, Polish Academy of Sciences, 25, Reymonta Str., 30-059 Kraków, Poland

2 Department of Chemistry and Corrosion of Metals, Faculty of Foundry Engineering, AGH University of Science and Technology, 23, Reymonta Str., 30-059 Kraków, Poland

3 Faculty of Mechanical Engineering and Robotics, AGH-University of Science and Technology, 30, Mickiewicza St., 30-059 Kraków, Poland crystallographic structures [2]. There were examples of sets of four or more elements within groups from III to XII of the periodic table, which crystallized as simple solid solutions of BCC [1] or FCC structures [2]. Recent studies have led to the development of hexagonal close-packed (HCP) alloys $[3,4]$ and new ones, such as high entropy alloys with eutectic mixtures [5], as well as composites reinforced with $\mathrm{SiC}$ [6] or $\mathrm{Al}_{2} \mathrm{O}_{3}$ [7] based on the HEA matrix. Further studies focused on improvement of the mechanical properties of HEAs by applying various processing methods, like rapid cooling [8], thixoforming [9] or thermal or thermomechanical treatments [10-12]. Depending on the applied method used to produce HEAs, such as powder metallurgy or casting, different phase compositions were obtained [13, 14]. For example, in an equal-atomic AlCoCrFeNi HEA in the as-cast state, a B2 ordered matrix and disordered BCC inclusions were identified $[1,13,15,16]$, while after the sintering of powders a multiphase composition consisting of an $\mathrm{Al}-\mathrm{Ni}$ phase, a tetragonal $\mathrm{Cr}-\mathrm{Fe}-\mathrm{Co}$ based $\sigma$ phase 
and Al-Ni-Co-Fe (FCC solid solution phase) was obtained [17]. The powder metallurgy process has an inherently nonequilibrium nature; however, high temperature annealing can lead to the equilibrium state being obtained and the formation of new phases [18]. Compared with casting, mechanical alloying (MA) is a more convenient method, which has been widely used for the synthesis of nanocrystalline materials with a uniform microstructure. It is known that the fine grain size largely contributes to the improved strength of materials via the Hall-Petch relation and grain boundary strengthening [19]. The application of rapid cooling of a liquid alloy can be an alternative route for refining the structure of the AlCoCrFeNi HEA [8]. Nevertheless, mechanical alloying is expected to reduce the preparation costs and widen the application scope of HEA.

A new approach to designing HEA is a switch from a well-developed equiatomic composition to a non-equiatomic system, which allows numerous combinations of chemical composition to be created, and thus the mechanical properties to be tailored according to applications. Li et al. [20] developed a new non-equiatomic system, called high entropy steel, to obtain the transformation induced plasticity, ensuring a significant increase in strength. There are several examples of $\mathrm{Al}-\mathrm{Co}-\mathrm{Cr}-\mathrm{Fe}-\mathrm{Ni}$ system optimization in the literature. In the Al16Co16Cr16Fe16Ni34 HEA, Wani et al. [21] obtained a eutectic consisting of B2-BCC plates and $\mathrm{L1}_{2}$-FCC structure, significantly improving strength and ductility. The influence of various $\mathrm{Al}$ content on the microstructure and properties was studied in [22-24]. Another approach consisted of adding alloying elements e.g. $\mathrm{Nb}$ [25], $\mathrm{Si}$ [26], $\mathrm{Cu}, \mathrm{Mo}$ [27] or Mn [28] to a five-component system. Most of the high entropy alloys have been prepared mainly by arc melt/casting methods [29-31]. Thus, there has been a large demand for studies of various $\mathrm{Al}-\mathrm{Co}-\mathrm{Cr}-\mathrm{Fe}-\mathrm{Ni}$ composition combinations obtained using powder metallurgy, which could lead to the production of materials with superior properties. The aim of the work was to study the phase formation, microstructural evolution, and mechanical properties of novel multi-component equi and non-equiatomic compositions, based on $\mathrm{Al}-\mathrm{Co}-\mathrm{Cr}-\mathrm{Fe}$ and $\mathrm{Al}-\mathrm{Co}-\mathrm{Cr}-\mathrm{Fe}-\mathrm{Ni}$ systems synthesized by high energy ball milling and consolidation by spark plasma sintering.

\section{Experimental Procedure}

Four compositions of high entropy alloys: A125Co$25 \mathrm{Cr} 25 \mathrm{Fe} 25 \mathrm{Al} 20 \mathrm{Co} 20 \mathrm{Cr} 20 \mathrm{Fe} 20 \mathrm{Ni} 20$, Al10Co30Cr$20 \mathrm{Fe} 35 \mathrm{Ni} 5$ and $\mathrm{A} 115 \mathrm{Co} 30 \mathrm{Cr} 15 \mathrm{Fe} 40 \mathrm{Ni} 5$ (all in at\%), were prepared from element blends of $\mathrm{Al}, \mathrm{Co}, \mathrm{Cr}, \mathrm{Fe}$ and Ni powders of high purity (99.5\%). This was done by mechanical alloying in a Fritsch Pulverisette-P5 high energy ball mill for $35 \mathrm{~h}$ at $200 \mathrm{rpm}$, at the ball to powder weight ratio of 10:1, using stainless steel vials and balls in N-heptane applied as the agent controlling the process. The prepared powders were consolidated using Spark Plasma Sintering (SPS), type HP D5 produced by FCT at $1050{ }^{\circ} \mathrm{C}$ for 15 min under 35-bar axial pressure in an argon atmosphere. The X-ray measurements of the phase composition were performed using a Philips PW1740 diffractometer and CoKa filtered radiation. The microstructure was examined using an FEI SEM XL30 scanning electron microscope equipped with an energy dispersive X-ray spectrometer (EDAX GEMINI 4000). The microstructure and selected area electron diffraction (SAED) studies were performed using a Tecnai G2 F20 transmission electron microscope (TEM). The micro-chemical analysis was conducted using scanning transmission (STEM) modes coupled with Integrated Energy-Dispersive X-ray spectroscopy (EDS). The chemical content analysis was carried out in three consecutive tests and the arithmetic average was calculated. The Vickers hardness was measured under the load of $5 \mathrm{~kg}$ using a Zwick/ZHU 250 tester. The compression test, according to the $\mathrm{PN}-57 / \mathrm{H}-04320$ standard, was performed on cylindrical samples of $4 \mathrm{~mm}$ diameter and $6 \mathrm{~mm}$ height. The wear properties of the HE alloys were evaluated using a ball-on-disc apparatus (dry conditions) with aluminum oxide silicon-nitride $\left(\mathrm{Al}_{2} \mathrm{O}_{3}\right)$ balls of $6 \mathrm{~mm}$ in diameter as the counter body in accordance with ASTMG99-95. The investigations were conducted at established test parameters: wear track of $5 \mathrm{~mm}$ diameter, rotation speed of $60 \mathrm{rpm}$, normal load of $5 \mathrm{~N}$ (FN), total number of cycles 32000 , and distance of wear track $1000 \mathrm{~m}(\mathrm{~s})$ at the temperature $22 \pm 2{ }^{\circ} \mathrm{C}$. After the tests, the profiles of wear tracks were measured with a stylus profile-meter and the AV area of the worn material was calculated. The wear rate WV was calculated after each test from the equation:

$W V=V / F N \cdot s$

where worn volume of material $\mathrm{V}$ is given by

$V=A V \cdot 2 \cdot \pi \cdot r$

where $\mathrm{r}$, wear track radius; FN, applied load; s, sliding distance. The friction force FT was measured during the tests by the precise load sensor and then the coefficient of friction was calculated according to the ratio:

$\mu=F T / F N$

\section{Results and Discussion}

Four different compositions of high entropy alloys based on $\mathrm{Al}-\mathrm{Co}-\mathrm{Cr}-\mathrm{Fe}$ and $\mathrm{Al}-\mathrm{Co}-\mathrm{Cr}-\mathrm{Fe}-\mathrm{Ni}$ were prepared, using mechanical alloying and consolidation by spark plasma sintering. The chemical compositions of the studied alloys were experimentally selected in order to obtain a $\mathrm{BCC}$ solid solution and mixtures of BCC with FCC phases. The overall 
Table 1 Overall chemical compositions and phase composition of studied alloys obtained using X-ray analysis

\begin{tabular}{llllllll}
\hline Compositions & \multicolumn{4}{l}{ Chemical composition (at\%) } & \multirow{2}{*}{ Phase composition (vol\%) } \\
\cline { 2 - 5 } & $\mathrm{Fe}$ & $\mathrm{Ni}$ & $\mathrm{Cr}$ & $\mathrm{Al}$ & $\mathrm{Co}$ & \\
\hline A125Co25Cr25Fe25 & 25.9 & - & 24.3 & 26.1 & 23.7 & $97.2 \%$ of BCC, $2.8 \%$ of carbides \\
A120Co20Cr20Fe20Ni20 & 19.8 & 21.1 & 20.5 & 19.4 & 19.2 & $73 \%$ of BCC, 24\% of FCC, 3\% of carbides \\
A110Co30Cr20Fe35Ni5 & 36.2 & 5.0 & 20.4 & 10.1 & 28.3 & $29.8 \%$ of BCC, 67.9\% of FCC, 2.3\% carbides \\
Al15Co30Cr15Fe40Ni5 & 41.1 & 4.8 & 15.4 & 14.7 & 24.0 & $59 \%$ of BCC, 37.9\% of FCC, 3.1\% carbides \\
\hline
\end{tabular}

Fig. 1 X-ray diffraction patterns of alloys: $a$ $\mathrm{A} 125 \mathrm{Co} 25 \mathrm{Cr} 25 \mathrm{Fe} 25, b$ A120Co20Cr20Fe20Ni20, $c$ $\mathrm{A} 110 \mathrm{Co} 30 \mathrm{Cr} 20 \mathrm{Fe} 35 \mathrm{Ni}$, $d$ $\mathrm{A} 115 \mathrm{Co} 30 \mathrm{Cr} 15 \mathrm{Fe} 40 \mathrm{Ni} 5$

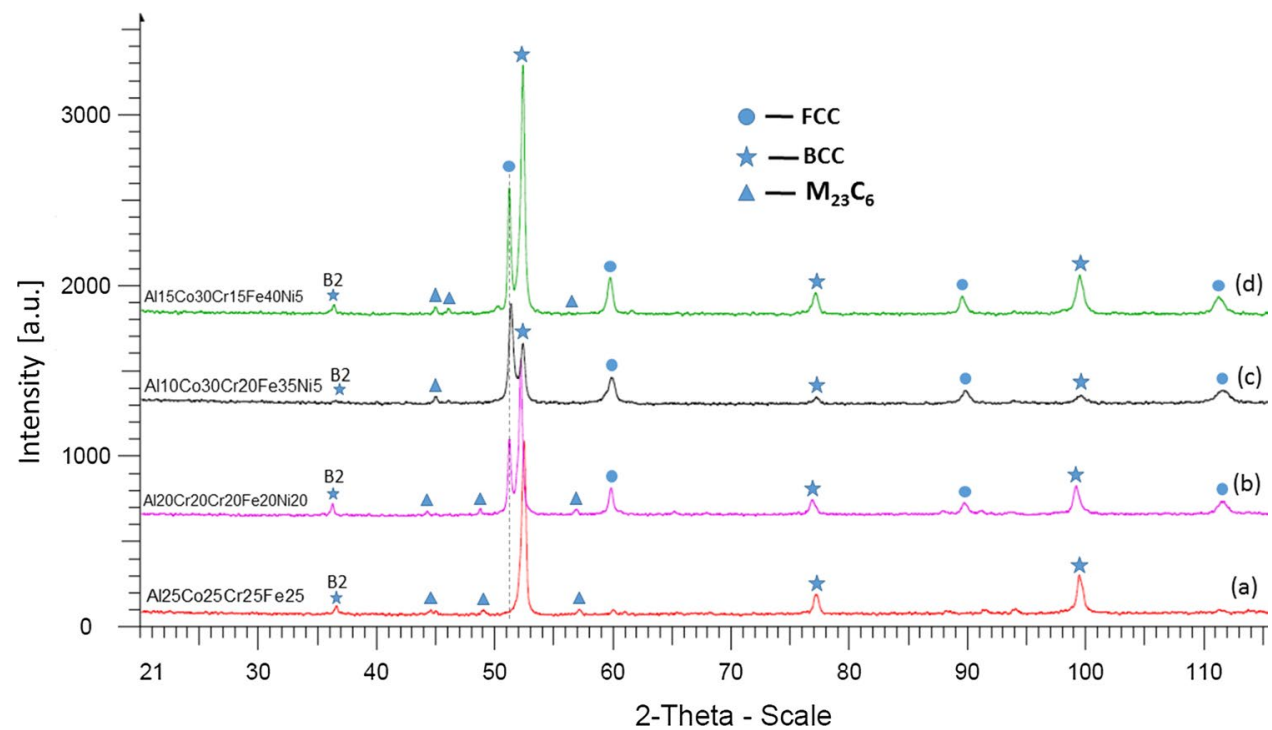

chemical composition of the investigated samples is presented in Table 1. The phase composition and the volume percent determined on the basis of X-ray diffraction patterns (Fig. 1) are included in Table 1.

\subsection{Microstructure Analysis of Al25Co25Cr25Fe25}

The A125Co25Cr25Fe25 four-element equiatomic system was studied in the first stage. The SEM-BSE analysis showed small changes of phase contrast in the area studied in the sample, which was connected with variable chemical compositions. A detailed analysis of the microstructure revealed large grains of 1-7 $\mu \mathrm{m}$ (Point 1 in Fig. 2; Table 2) surrounded by an additional small grains (Points 2 and 3 in Fig. 2; Table 2). It can be observed that the concentration of elements in the grain areas is close to equiatomic, but there is strong $\mathrm{Cr}$ segregation at their boundaries. The X-ray analysis (Fig. 1a) confirmed the presence of two BCC structures: solid solutions with partial B2 ordering (which could be based on the Al-Fe-Co composition [32]). Additionally, characteristic peaks from $\mathrm{M}_{23} \mathrm{C}_{6}$ carbides (below 2.8 vol\%) were identified in the pattern.

High magnification obtained using TEM microscopy in the bright field mode of the grain area revealed a microstructure consisting of fine spherical sub-grains of 50-200 nm

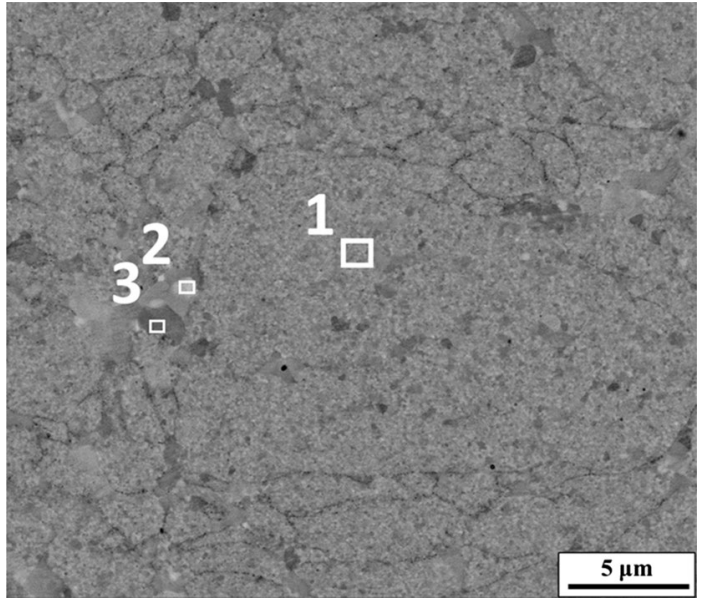

Fig. 2 SEM microstructures with marked locations of EDS analysis of the $\mathrm{A} 125 \mathrm{Co} 25 \mathrm{Cr} 25 \mathrm{Fe} 25 \mathrm{HEA}$

in size (Fig. 3a). Differences in the contrast between grains could be connected with various crystallographic structures and orientations. The electron diffraction patterns in the selected area confirmed that they had the same bodycentered cubic structure (Fig. 3b, c) but a different chemical composition (Points 1 and 2, Fig. 3a; Table 2). A strong 
$\mathrm{Cr}$ and $\mathrm{Al}$ segregation is visible. The TEM-STEM analysis demonstrates that the microstructure consists of spherical grains (Fig. 4a). The mapping of element distribution (Fig. 4b-e) shows that the matrix contains grains with a high concentration of $\mathrm{Al}, \mathrm{Co}$ and $\mathrm{Fe}$, in which $\mathrm{Cr}$-enriched spherical phases are embedded. The microstructure obtained has features of a composite with homogeneously distributed $\mathrm{Cr}$ grains, which is perhaps due to the fact that chromium has a higher melting point than $\mathrm{Fe}, \mathrm{Co}$ and $\mathrm{Al}$, and its diffusivity is lower than that of the other elements [33, 34]. It also should be noted that chromium tends to form oxides on the surface of particles and in consequence it could limit reaction with other elements. Nevertheless, the evolution of a bodycentered solid solution can be attributed to the presence of strong $\mathrm{BCC}$ forming elements, such as $\mathrm{Cr}, \mathrm{Fe}$ and $\mathrm{Al}$ [35]. It should be noted that aluminum is the strongest stabilizer of the BCC structure in the present system [36]. In studies conducted by Praveen et al. [37], who obtained the same alloy
Table 2 Chemical composition of the $\mathrm{A} 125 \mathrm{Co} 25 \mathrm{Cr} 25 \mathrm{Fe} 25 \mathrm{HEA}$ measured by SEM-EDS as well as TEM/EDS (areas marked in Figs. 2 and $3 a$ )

Fig. 3 BF TEM microstructure of the $\mathrm{A} 125 \mathrm{Co} 25 \mathrm{Cr} 25 \mathrm{Fe} 25$ HEA showing fine grains with places marked with numbers of EDS analysis (a), SAEDPs obtained of areas marked in (a) as circles $(\mathbf{b}, \mathbf{c})$

\begin{tabular}{lllllll}
\hline EDS analysis & Place of analysis & \multicolumn{2}{l}{ Element $($ at\% $)$} & & \\
\cline { 3 - 7 } & & $\mathrm{Al}$ & $\mathrm{Co}$ & $\mathrm{Cr}$ & $\mathrm{Fe}$ & $\mathrm{Ni}$ \\
\hline Figure 2 (SEM) & 1 & 26.3 & 26.9 & 17.3 & 29.2 & 0.3 \\
& 2 & 14.4 & 25.7 & 31.1 & 28.8 & - \\
Figure 3a (TEM) & 3 & 10.1 & 12.2 & 58.0 & 19.7 & - \\
& 1 & 24.8 & 32.3 & 12.0 & 30.0 & 0.9 \\
& 2 & 2.8 & 3.5 & 80.2 & 13.3 & - \\
\hline
\end{tabular}

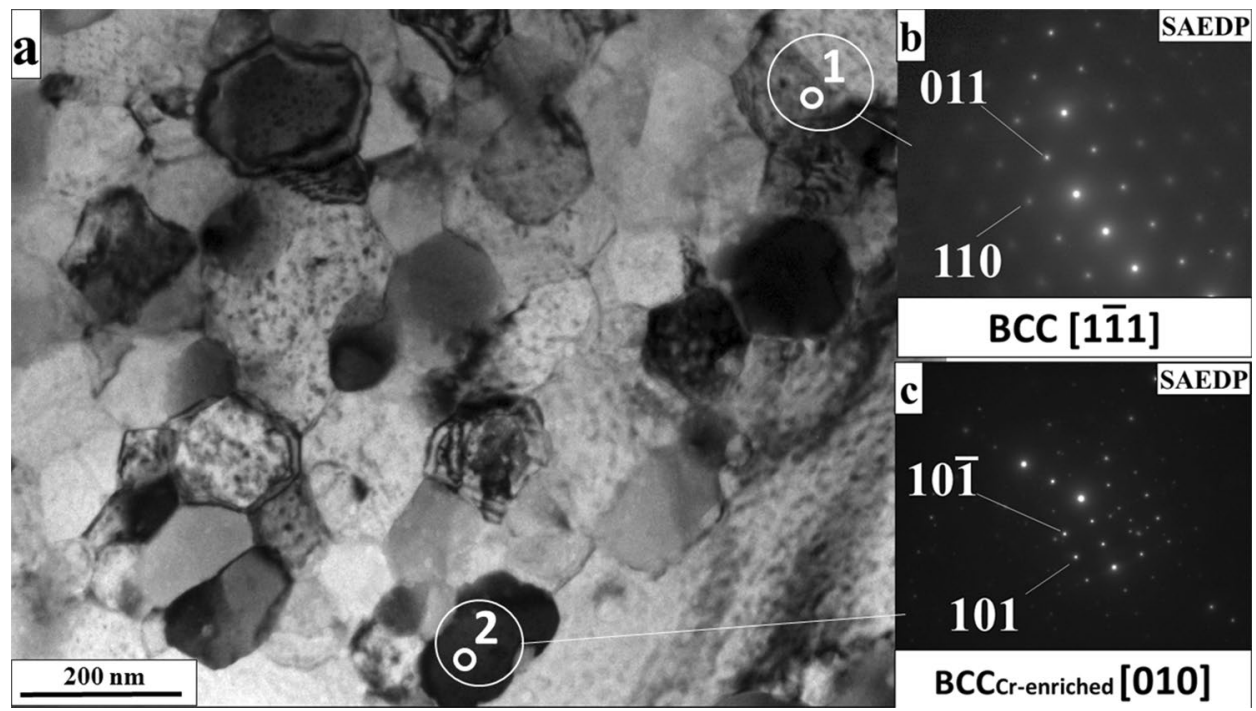

Fig. 4 STEM image of the A125Co25Cr25Fe25 HEA with a large frame of the mapping area (a) and surface distributions of alloy constituents: $\mathbf{b ~ A l}$; c $\mathrm{Cr} ; \mathbf{d} \mathrm{Co} ; \mathbf{e} \mathrm{Fe}$
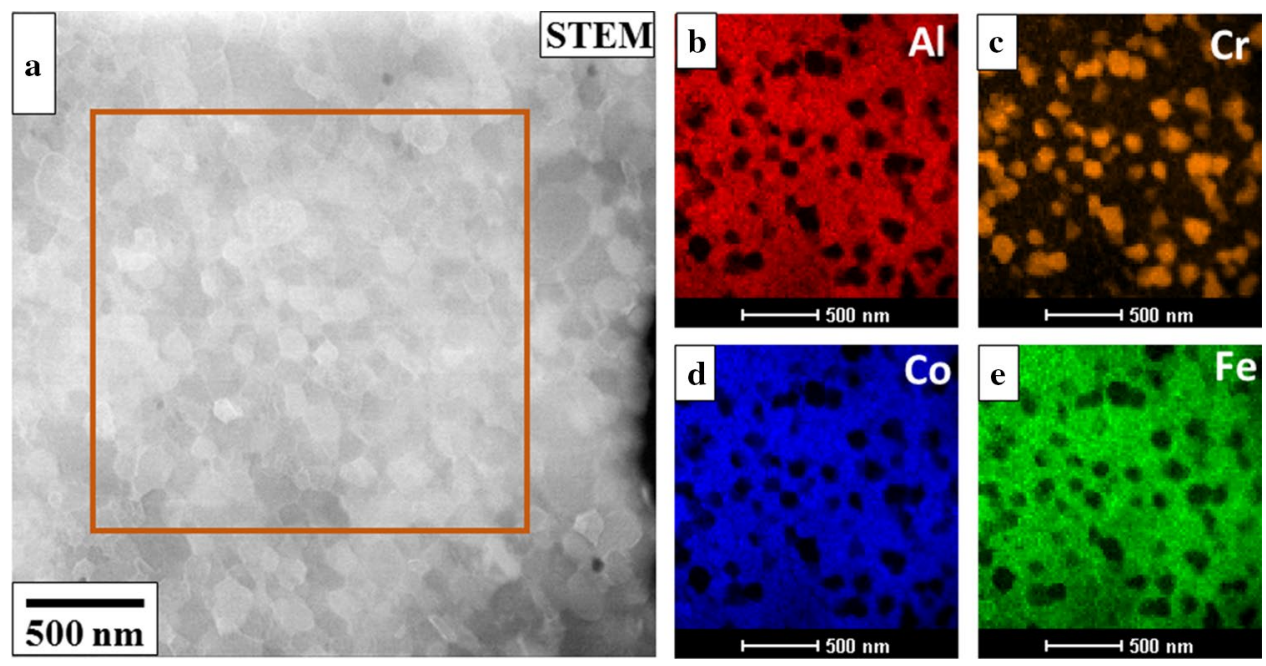
using MA and sintering, the $\sigma$-phase was additionally identified (together with $\mathrm{M}_{23} \mathrm{C}_{6}$ carbides) using diffraction analysis. Presently, its lack of sigma, or its smaller concentration, is connected with a longer milling time $(35 \mathrm{~h})$, as well as with a higher sintering temperature $\left(1050{ }^{\circ} \mathrm{C} / 15 \mathrm{~min}\right)$. Different conditions of mechanical synthesis led to an increased contamination with carbon, coming from PCA as well as from the container and balls. It is well known that carbon is a strong carbide forming element [38]. According to the Ellingham dependence $[39,40]$, the Gibbs energy for the $\mathrm{M}_{23} \mathrm{C}_{6}$ creation is lower than that for the $\sigma$-phase. The extra amount of carbon, which belongs to interstitial elements, has an influence on solid solution strengthening. However, its direct impact is difficult to analyze.

\subsection{Microstructure Analysis of the Al20Co20Cr20Fe20Ni20 HEA}

The addition of nickel, which stabilizes the FCC structure [41], to the four-element $\mathrm{Al}-\mathrm{Co}-\mathrm{Cr}-\mathrm{Fe}$ system led to the formation of a multiphase microstructure. The SEM-BSE image of the Al20Co20Cr20Fe20Ni20 HEA (Fig. 5) showed a dark matrix (75.5 vol\%) with an increased amount of $\mathrm{Cr}$ (up to 40 at\%, Point 1 in Fig. 5; Table 3), and a bright

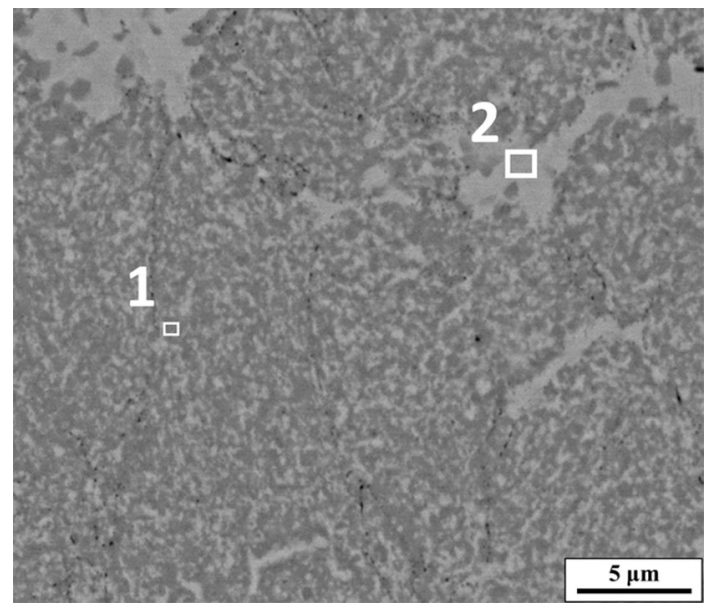

Fig. 5 SEM microstructures of the Al20Co20Cr20Fe20Ni20 HEA with marked locations of EDS analysis contrasted second phase (24.5 vol\%) enriched mainly in $\mathrm{Co}$ and Fe (Point 2 in Fig. 5; Table 3). Due to the fact that the bright phase contained a predominant amount of the element stabilizing the austenite in steel [42], it was believed that it had an FCC structure. Additionally, X-ray analysis (Fig. 1b) confirmed the presence of a significant amount of the BCC solid solution (visible as dark areas in Fig. 5) with a smaller concentration of the FCC structure, as well as with $\mathrm{M}_{23} \mathrm{C}_{6}$ carbides. It should be noted that the small black areas in the micrographs were pores (Fig. 5) in the specimen.

The TEM studies of the AlCoCrFeNi HEA (Fig. 6a) confirmed the presence of a fine grain structure, with the average grain size of $65 \mathrm{~nm}$, giving a complex contrast probably due to a different orientation and different chemical composition. Another TEM-BF image with marked points of EDS analysis (Fig. 6b) showed a large island of grains over $0.5 \mu \mathrm{m}$ large and a chemical composition corresponding to the elements stabilizing the face-centered cubic structure i.e. $\mathrm{Co}, \mathrm{Fe}$ and $\mathrm{Ni}$ (Points 1 and 2 in Fig. 6b; Table 3). That was also confirmed by the electron diffraction, which showed the FCC structure of large grains with a zone axis [10-1] (Fig. 6c). Another EDS analysis showed grains with a high Cr concentration (Point 3, Fig. 6b; Table 3). The SAEDP from a similar area allowed the identification of the $\sigma$-phase with a tetragonal structure and zone axis [2-11] (Fig. 6d). The electron diffraction pattern (Fig. 6e) confirmed the presence of the BCC solid solution. Such a structure resulted probably from a high $\mathrm{Al}$ concentration which stabilized that type of lattice [42]. Additionally, at Point 4, Fig. 6b, an increased concentration of $\mathrm{Ni}$ and $\mathrm{Al}$ was registered, suggesting the existence of a $\mathrm{B} 2$ ordered $\mathrm{NiAl}$ phase. It is well known that aluminum together with Ni could form precipitations of ordered $\mathrm{NiAl}$ [43-45] or $\mathrm{Ni}_{3} \mathrm{Al}[40,46]$.

Analyzing the TEM images, it becomes obvious that there are two different grain sizes, one larger than $500 \mathrm{~nm}$ and another in the range of $65 \mathrm{~nm}$. The SAED patterns indicate that the smaller particles have a BCC structure of the $\sigma$-phase while the larger ones have an FCC structure. This can be directly connected with the diffusivity of elements responsible for the phase formation [47]. It could be assumed that grains are usually smaller in places where the Cr concentration is high.
Table 3 Chemical composition of the $\mathrm{A} 120 \mathrm{Co} 20 \mathrm{Cr} 20 \mathrm{Fe} 20 \mathrm{Ni} 20$ HEA measured by SEM-EDS and by TEM/EDS (areas marked in Figs. 5, 6b)

\begin{tabular}{llrrrrr}
\hline Place EDS of analysis & \multicolumn{7}{c}{ Element (at\%) } & & \\
\cline { 2 - 6 } & & Al & Co & Cr & Fe & Ni \\
\hline Figure 5 (SEM) & 1 & 8.3 & 12.4 & 40.3 & 14.7 & 18.6 \\
Figure 6b (TEM) & 2 & 13.9 & 24.6 & 19.3 & 32.5 & 15.2 \\
& 1 & 3.8 & 22.2 & 26.9 & 35.0 & 12.1 \\
& 2 & 6.2 & 23.5 & 23.6 & 33.7 & 13.0 \\
& 3 & 10.6 & 17.8 & 45.0 & 14.7 & 11.9 \\
& 4 & 36.1 & 2.2 & 12.6 & 18.8 & 30.3 \\
\hline
\end{tabular}


Fig. 6 TEM microstructure of the Al20Co20Cr20Fe20Ni20 HEA (a), BF image with fine grains, with marked places of EDS analysis (b), selected area diffraction patterns (c-e)

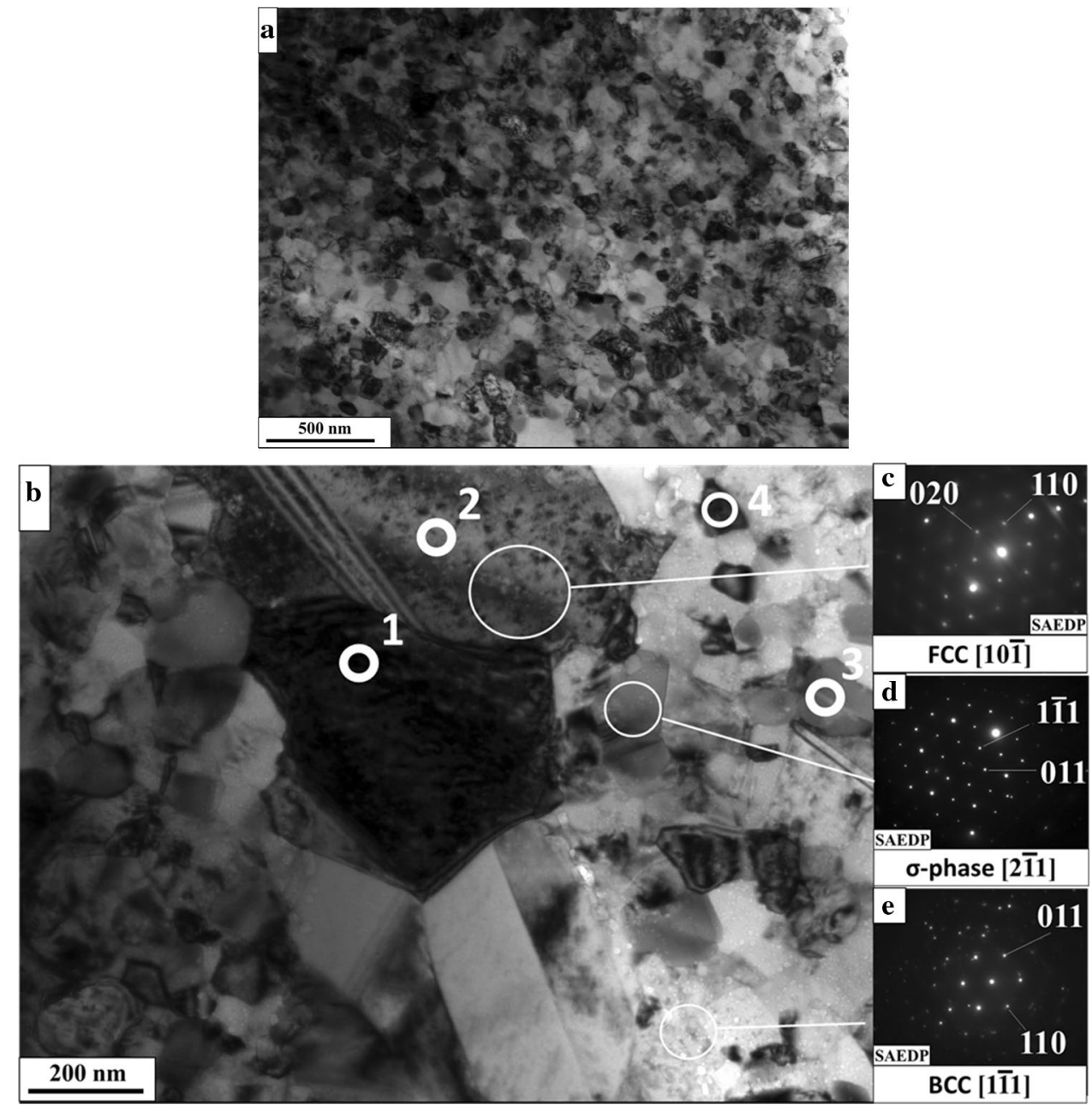

In order to determine the distribution of elements in the microstructure, a qualitative chemical analysis was conducted using TEM operated in the STEM mode. The bright contrast features in Fig. 7a represent the area of small grains. The analyzed area is marked with a frame and the results are shown in the form of maps of individual elements (Fig. 7b-f). Since STEM imaging is quite sensitive to differences in chemical compositions it can detect chemical segregation. The various intensity of color contrast suggests a different concentration of elements. Four areas of various composition can be distinguished: (a) $\mathrm{Al}-\mathrm{Ni}-\mathrm{Co}$, (b) $\mathrm{Cr}-$ enriched, (c) $\mathrm{Fe}-\mathrm{Co}-\mathrm{Ni}-\mathrm{Cr}$ and (d) $\mathrm{Fe}-\mathrm{Co}-\mathrm{Cr}$, which could correspond to AlNi-B2, the BCC phase, FCC or BCC solid solution and the $\sigma$-sigma phase, respectively.

Mohanty et al. [17] reported that the AlCoCrFeNi microstructure consisted of a small amount of the Al-Ni enriched phase (below 3\%), $\sigma$ phase and $\mathrm{Al}-\mathrm{Ni}-\mathrm{Co}-\mathrm{Fe}$ FCC solid solution in the sample sintered in the range of $700-1000{ }^{\circ} \mathrm{C}$ using SPS. Differences between our results and those obtained by [17] (absence of BCC solid solution) could have been caused by a higher temperature and longer sintering time, as well as different milling conditions. It could be assumed that the structure described in the work [1] is strongly metastable. Ji et al. [13] annealed the AlCo$\mathrm{CrFeNi} \mathrm{HEA}$ powder at $900{ }^{\circ} \mathrm{C}$ for $5 \mathrm{~h}$, next sintered it and obtained a dual phase structure consisting of FCC and BCC in a similar ratio. This proves that the phase composition of the studied alloy is strongly dependent on technological parameters and the preparation method. Significant differences in comparison with casting, in which the $\mathrm{AlCrFeCoNi}$ HEA has the BCC + B2 crystal structure [14], are connected with the increased solid solubility in the mechanical alloying process.

\subsection{New Non-equiatomic Composition of Al-Co-Cr- $\mathrm{Fe}-\mathrm{Ni}$}

The entropy-maximized equiatomic four-five element alloy often reveals a complex multiphase microstructure containing intermetallic phases [41]. This confirms that a high entropy effect contribution to the stabilization of the matrix is often not sufficient to over-compensate the enthalpy 


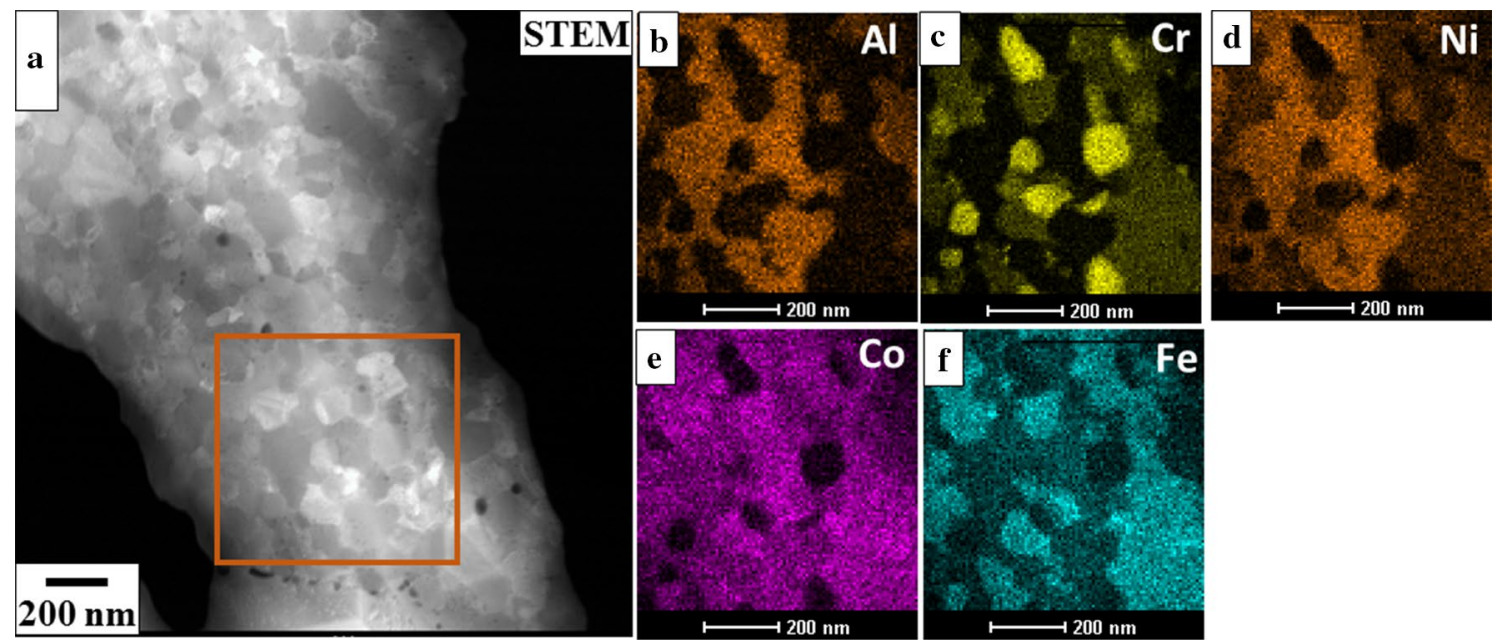

Fig. 7 STEM image of the A120Co20Cr20Fe20Ni20 HEA with a large frame of the mapping area (a) and surface distributions of alloy constituents: b Al; c Cr; d Ni; e Co; f Fe

advantages of competing intermetallic phases [42]. This might also be the reason why truly single high-entropy phases have been obtained only for a few compositions. Introducing a non-equiatomic mixing rule would provide a much larger compositional space for synthesizing high entropy alloys [20]. When designing high entropy alloys, two main factors should be taken into account: the appropriate combination of FCC to BCC solid solutions as well as the mechanical stability of the face-centered cubic structure. These factors play a crucial role in the mechanical properties [41]. Generally, the modeling of phase diagrams (e.g. Calphad, Thermo-calc) was used in several works to support the design process [41, 42, 48, 49]. However, this refers mainly to equilibrium systems. Powder metallurgy, applied in our experiments (mechanical synthesis and sintering) to produce a new composition of the high entropy alloy, is recognized as a strong non-equilibrium process. It is a completely different mechanism of phase formation than in casting. As a consequence, a strong tendency towards segregation and the formation of non-equilibrium phases leads to significantly different phase compositions than after typical melting. For example, in the Al20Co20Cr20Fe20Ni20 HEA in the as-cast state, a BCC-B2 structure was present, while in the same system produced by powder metallurgy a mixture of FCC and BCC structures was obtained [1, 13, 15-17] This was due to the high strain, strong deformation and nano-size structure (more reactive) of the milled powder, as well as the presence of oxides which, consequently, could enhance the formation of non-equilibrium compounds.

In the present work, based on experimental results (trial and error), two five-element high entropy systems of nonequal-volume atomic concentration were designed: Al10Co$30 \mathrm{Cr} 20 \mathrm{Fe} 35 \mathrm{Ni} 5$ and $\mathrm{A} 115 \mathrm{Co} 30 \mathrm{Cr} 15 \mathrm{Fe} 40 \mathrm{Ni}$. It can be seen that the elements controlling the type of solid solution in the present system are $\mathrm{Ni}$ and $\mathrm{Al}$. It is well known that nickel enhances the austenite phase field in steel [20, 42], while aluminum promotes the formation of a BCC structure [20, 24]. Furthermore, together they can form NiAl type precipitations of an ordered structure [43-46].

A general approach to the formation of solid solutions in HEAs can be reasonably predicted using parametric approaches based on the topological, thermodynamic and physical properties of constituent alloying elements, like atomic radii, mixing enthalpies and entropy between any two elements [50, 51]. However, these parametric approaches do not provide much information about the crystal structure of the achieved solid solutions. The thermodynamic and topological parameters calculated for the alloys developed in the present work are summarized in Table 4 . Based on several experimental studies conducted in [52], $\Delta \mathrm{H}_{\text {mix }}, \delta$ and VEC are the most significant parameters.

VEC (electron valence) affects the phase stability in various solid solutions forming HEAs (comprising different alloying elements) [50-53]. The FCC phases occur at $\mathrm{VEC} \geq 8.0, \mathrm{BCC}$ phases at $\mathrm{VEC}<6.87$, and a mixture of $\mathrm{FCC}$ and $\mathrm{BCC}$ phases at $6.87 \leq \mathrm{VEC}<8$. The type of solid solution experimentally obtained in the present work (Table 1) is in accordance with the approach proposed by Guo et al. [53] to predict HEA structure, although this method (the VEC concentration) was not previously validated for the material obtained by powder metallurgy.

Zhang et al. [52] were the first to propose combined thermodynamic and topological parameters (specifically $\Omega \sim \delta$ and $\Delta \mathrm{H}_{\text {mix }} \sim \delta$ maps) to predict the phase formation of HEA systems. They collated the absolute $\Delta \mathrm{H}_{\text {mix }}$, HEA values at different compositions with $\delta$ (atomic size difference) in one diagram, creating a map of dependencies, in which the type of solid solution was marked. It was revealed that FCC 
Table 4 Phase constitution and lattice constants, entropy of mixing $\left(\Delta \mathrm{S}_{\text {mix }}\right)$, enthalpy of mixing $\left(\Delta \mathrm{H}_{\text {mix }}\right)$, average melting point, $\left(\mathrm{T}_{\mathrm{m}}\right)$, parameter $\Omega$-combining effects of $\Delta \mathrm{S}_{\text {mix }}, \Delta \mathrm{H}_{\text {mix }}$ and $\mathrm{T}_{\mathrm{m}}$ electron- egativity difference (ksi), atomic size difference $(\delta)$, and valence electron concentration (VEC), for the HEAs developed in the present work

\begin{tabular}{|c|c|c|c|c|c|c|c|c|c|}
\hline System & Crystal structure & $\begin{array}{l}\text { Lattice con- } \\
\text { stant }(\AA)\end{array}$ & $\begin{array}{l}\Delta \mathrm{s}_{\text {mix }} \\
\left(\mathrm{JK}^{-1} \mathrm{~mol}^{-1}\right)\end{array}$ & $\Delta \mathrm{H}_{\operatorname{mix}}\left(\mathrm{kJ} \mathrm{mol}^{-1}\right)$ & $\Delta_{\mathrm{Tm}}(\mathrm{K})$ & $\Omega$ & $\Delta \chi$ & $\delta$ & VEC \\
\hline $\mathrm{A} 125 \mathrm{Co} 25 \mathrm{Cr} 25 \mathrm{Fe} 25$ & $\mathrm{BCC}$ & 2.865 & 11.53 & -11.5 & 1673 & 1.00 & 0.11 & 6.2 & 6.5 \\
\hline \multirow[t]{2}{*}{$\mathrm{A} 120 \mathrm{Co} 20 \mathrm{Cr} 20 \mathrm{Fe} 20 \mathrm{Ni} 20$} & FCC & 3.591 & 13.38 & -12.32 & 1684 & 1.83 & 0.12 & 5.78 & 7.2 \\
\hline & $\mathrm{BCC}$ & 2.879 & & & & & & & \\
\hline \multirow[t]{2}{*}{ Al10Co30Cr20Fe35Ni5 } & FCC & 3.576 & 11.89 & -7.14 & 1780 & 1.66 & 0.10 & 4.41 & 7.5 \\
\hline & $\mathrm{BCC}$ & 2.870 & & & & & & & \\
\hline \multirow[t]{2}{*}{ Al15Co30Cr15Fe40Ni5 } & FCC & 3.585 & 11.91 & -8.66 & 1719 & 1.37 & 0.10 & 5.23 & 7.3 \\
\hline & BCC & 2.870 & & & & & & & \\
\hline
\end{tabular}

solid solutions tended to have larger $\Delta \mathrm{H}_{\text {mix }}$ and lower $\delta$ values, while the BCC solid solutions exhibited lower $\Delta \mathrm{H}_{\text {mix }}$ and larger $\delta$ values. When $\delta$ exceeded $6.6 \%$, solid solutions gave way to intermetallic compounds. It should be noted that there may be a mixture of BCC and FCC solid solutions for intermediate $\Delta \mathrm{H}_{\text {mix }}$ and $\delta$. Comparing the values of $\Delta \mathrm{H}_{\text {mix }}$ and $\delta$ obtained in the present work, it can be seen that they are within the range of occurrence of a single BCC or a mixture of FCC and BCC solid solutions, according to the map developed by Zhang et al. [52]. This proves that the powder metallurgy method is also appropriate for the prediction of this structure type.

To recap, the relative prevalence of entropy over enthalpy can be evaluated using the $\Omega$ parameter, which combines the effects of $\Delta \mathrm{S}_{\text {mix }}$ and $\Delta \mathrm{H}_{\text {mix }}$ [52]. When $\Omega \gg 1$, the entropy effect overwhelms the enthalpy one and, thus, the formation of solid solutions is likely, especially if the atomic size difference is small. This trend can be achieved by mixing multiple elements at equi- or near-molar ratios, as was done in HEAs.

\subsection{Al15Co30Cr15Fe40Ni5 HEA}

In the $\mathrm{Al} 15 \mathrm{Co} 30 \mathrm{Cr} 15 \mathrm{Fe} 40 \mathrm{Ni} 5 \mathrm{HEA}$, in which the $\mathrm{Al}$ concentration was decreased to 15 at $\%$ and Ni to 5 at $\%$, with a simultaneous increase in the volume of $\mathrm{Fe}$ and $\mathrm{Co}$ (in relation to the equiatomic system), the presence of predominant amounts of the BCC solid solution at small FCC concentrations (Fig. 1d; Tables 1 and 4) was noted. Aluminum is the key element controlling the type of solid solution in the studied system [24]. It was shown in [54] that it can influence the mechanical properties, mainly the strain hardening ability. The SEM microstructure showed a dark contrasted matrix with the amount of $61 \mathrm{vol} \%$, containing a high concentration of $\mathrm{Cr}$ and $\mathrm{Al}$ (Point 1, Fig. 8a; Table 5). Additionally, the EDS point analysis from the bright area (Point 2, Fig. 8a; Table 5) revealed the presence of 48 at $\%$ of Fe and 25 at $\%$
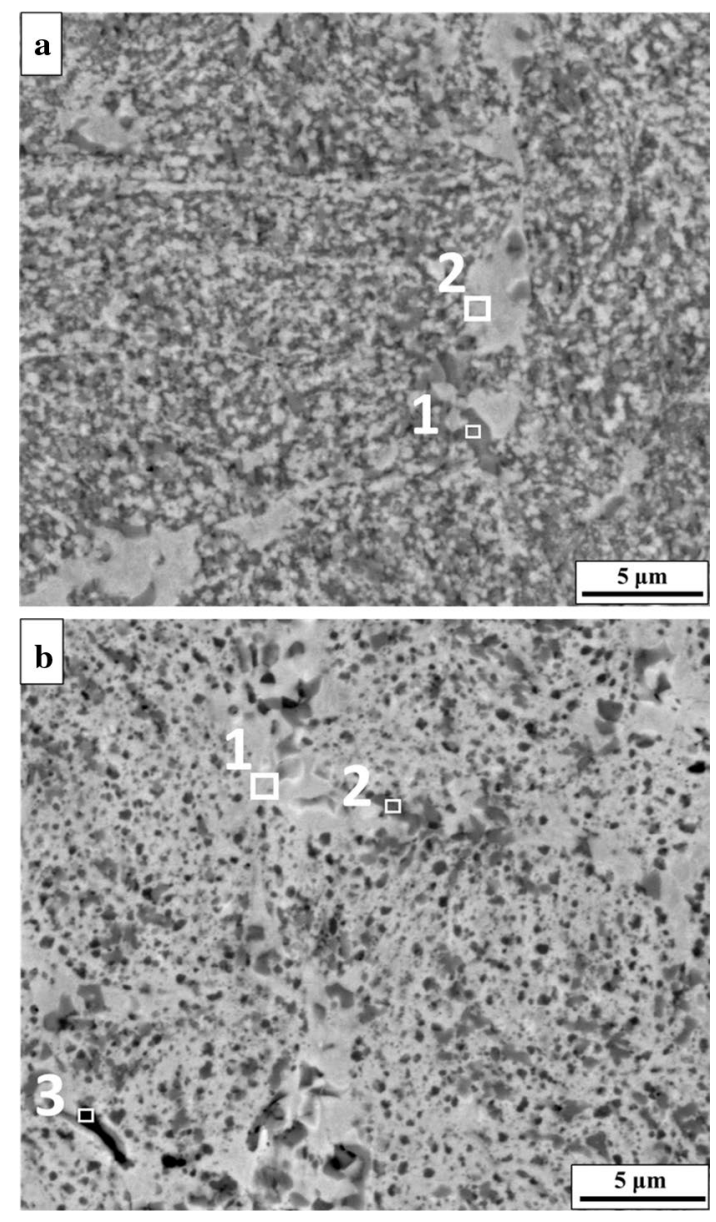

Fig. 8 SEM microstructures with marked locations of EDS analysis of a Al15Co30Cr15Fe40Ni5, b Al10Co30Cr20Fe35Ni5

of $\mathrm{Co}$, with the 27 at $\%$ concentration of other elements ( $\mathrm{Al}$, $\mathrm{Co}$ and $\mathrm{Ni}$ ), indicating an FCC structure.

Figure 9 presents the TEM bright field image of the Al15Co30Cr15Fe40Ni5 HEA. The microstructure consists of FCC solid solution mixtures (Figs. 1d, 9a, b) with high concentrations of Fe and Co (Point 1, Fig. 9a; Table 5), a BCC structure of grains (Fig. 9c, Point 2, Fig. 9a; Table 5) 
and $M_{7} C_{3}$ carbides of $100-400 \mathrm{~nm}$ in size (Fig. $9 \mathrm{~d}$ ). An additional study of element distribution, using TEM-STEM, is presented in Fig. 10. The analyzed area is marked with a frame and the results are shown in the form of maps of individual element distributions (Fig. 10b-f). Three essential areas of different compositions can be distinguished:
$\mathrm{Al}-\mathrm{Ni}-\mathrm{Co}, \mathrm{Fe}-\mathrm{Co}-\mathrm{Cr}$ and $\mathrm{Cr}-\mathrm{Fe}$, which may respectively correspond to: the AlNi-B2 ordered lattice, FCC solid solution and sigma or carbide precipitations. As can be seen, the multiphase structure is the result of a strong interaction between $\mathrm{Al}, \mathrm{Ni}$ and $\mathrm{Cr}$ in the studied $\mathrm{Al}-\mathrm{Co}-\mathrm{Cr}-\mathrm{Fe}-\mathrm{Ni}$ system.
Table 5 Chemical composition HEA measured by SEM-EDS as well as TEM/EDS (areas marked in Figs. 8a and 9a) of the Al15Co30Cr15Fe40Ni5

\begin{tabular}{lllllll}
\hline Place of analysis & \multicolumn{7}{l}{ Element (at\%) } & & \\
\cline { 2 - 6 } & & $\mathrm{Al}$ & $\mathrm{Co}$ & $\mathrm{Cr}$ & $\mathrm{Fe}$ & $\mathrm{Ni}$ \\
\hline Figure 8a (SEM) & 1 & 17.5 & 19.5 & 31.8 & 25.9 & 5.3 \\
Figure 9a (TEM) & 2 & 8.2 & 25.5 & 13.1 & 48.5 & 4.7 \\
& 1 & 5.7 & 25.4 & 13.2 & 52.0 & 3.7 \\
& 2 & 38.7 & 25.0 & 2.7 & 25.0 & 8.6 \\
\hline
\end{tabular}

Fig. 9 TEM microstructure of the $\mathrm{A} 115 \mathrm{Co} 30 \mathrm{Cr} 15 \mathrm{Fe} 40 \mathrm{Ni} 5$ HEA, a BF image with marked places of EDS analysis, $\mathbf{b}-\mathbf{d}$ selected area diffraction patterns

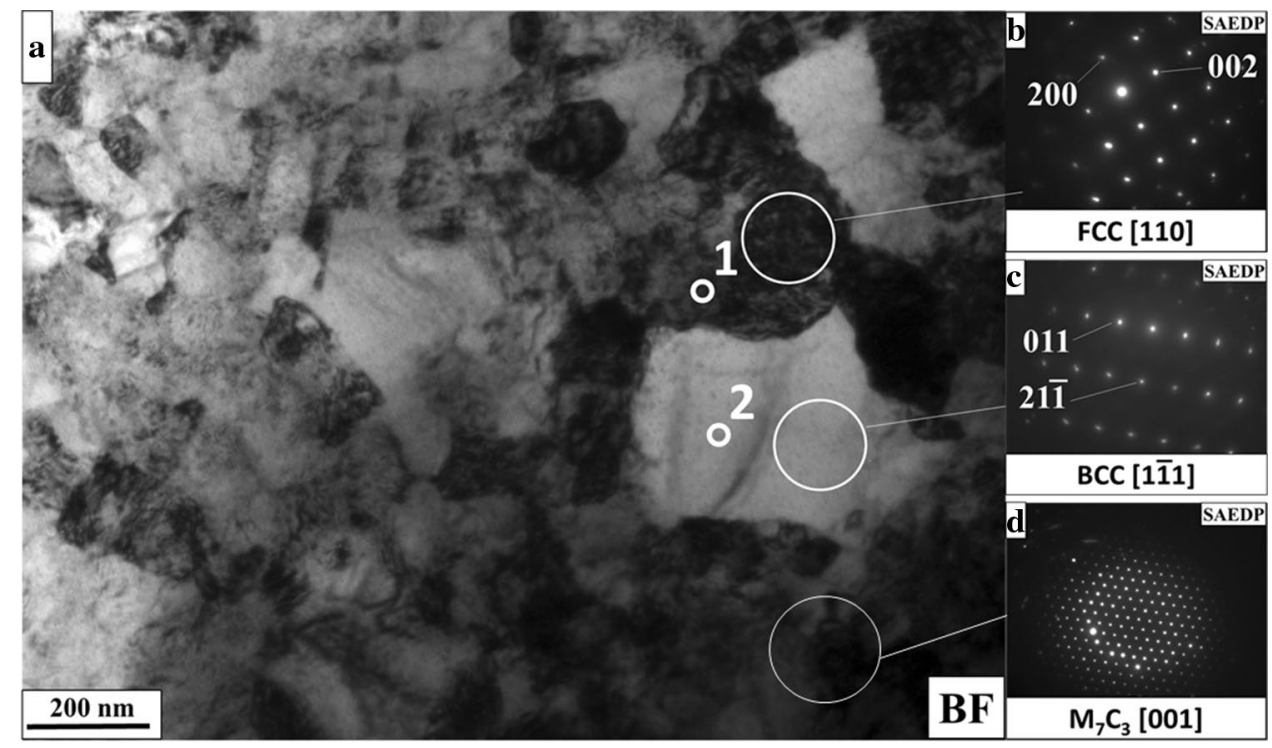

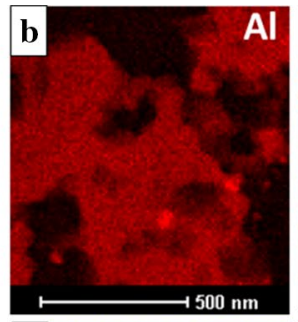
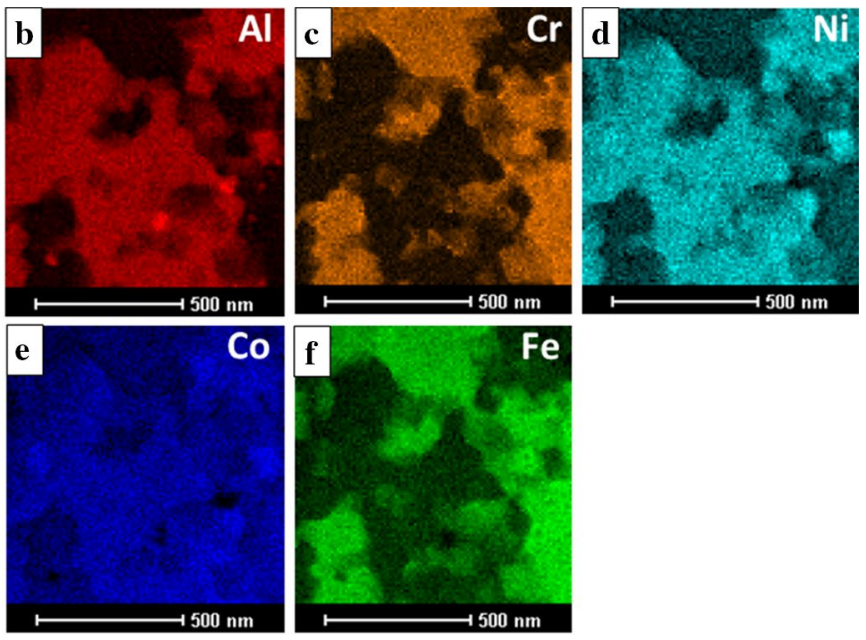

Fig. 10 STEM image of the Al15Co30Cr15Fe40Ni5 HEA with a large frame of the mapping area (a) and surface distributions of alloy constituents: b $\mathrm{Al} ; \mathbf{c} \mathrm{Cr} ; \mathbf{d} \mathrm{Ni} ; \mathbf{e} \mathrm{Co} ; \mathbf{f} \mathrm{Fe}$ 
The A110Co30Cr20Fe35Ni5 HEA has a predominant amount of FCC solid solution with a smaller concentration of BCC (Fig. 1c; Table 1). SEM-EDS analysis shows a complex microstructure, which consists of a light matrix (67.9 vol\%) enriched in $\mathrm{Co}, \mathrm{Fe}$ and $\mathrm{Ni}$ (Point 1, Fig. 8b; Table 6) with an FCC structure. Dark (29.8 vol\%) and black (2.3 vol\%) contrasted phases containing a high concentration of $\mathrm{Cr}$ (Point 2, Fig. 8b; Table 6) and an increased concentration of elements stabilizing the BCC structure (Point 3, Fig. 8b; Table 6) were identified inside the matrix.

Figure 11a shows a TEM micrograph of the Al10Co$30 \mathrm{Cr} 20 \mathrm{Fe} 35 \mathrm{Ni} 5 \mathrm{HEA}$ sintered sample. The bright field image presents a cocktail-like microstructure consisting of a few phases of 50-300 $\mathrm{nm}$ in diameter, distinguishable from each other thanks to the changeable contrast. The electron diffractions from the areas, marked with a ring in the micrograph (Fig. 11a), allowed the phases in the alloy to be identified. Based on the distances between the reflections and the angle between them, the FCC solid solution with [1-10] a zone axis (Fig. 11b), Ni(Co, Fe)Al with [021] orientation (Fig. 11c) and $\mathrm{M}_{7} \mathrm{C}_{3}$ with [211] a zone axis (Fig. 11d) were identified. Additionally, EDS analyses from the areas marked as 1 and 2 in Fig. 11a (Table 6) correspond to the phases established using diffraction patterns included in Fig. 11b, c. Another analysis at Point 3 in Fig. 11a (results in Table 6) corresponds to the phase found in the diffraction pattern included in Fig. 11d (on another TEM image micrograph). The presence of additional reflections, e.g. in Fig. 11d, (besides the main ones) in carbide diffraction could be connected with the existence of a high density of plane faults [55]. A similar effect was visible in the $\mathrm{Mg} 12 \mathrm{ZnY}$ alloy, where the structure of grains has a long-period stacking-order (LPSO) [56]. However, this phenomenon requires further studies.

The TEM-STEM image (Fig. 12a) with a mapping distribution of elements from the area of $500 \times 500 \mathrm{~nm}$ (Fig. 12b-f) confirmed a quite homogeneous distribution of $\mathrm{Co}$ (Fig. 12e) with continuous segregation of $\mathrm{Cr}, \mathrm{Fe}, \mathrm{Ni}$ and Al. This is a consequence of the formation of a multiphase structure, which gives materials specific mechanical properties.

Summarizing, the differences in the element composition of the four-five-component alloys are as follows:
Table 6 Chemical composition of the Al10Co30Cr20Fe35Ni5 HEA measured by SEM-EDS as well as TEM/EDS (areas marked in Figs. 8b and 11a)
Fig. 11 TEM microstructure of the Al10Co30Cr20Fe35Ni5 HEA with marked places of EDS analysis, a selected area diffraction patterns $(\mathbf{b}-\mathbf{d})$

\begin{tabular}{|c|c|c|c|c|c|c|}
\hline \multirow[t]{2}{*}{ Place of EDS analys } & & \multicolumn{5}{|c|}{ Element (at\%) } \\
\hline & & $\overline{\mathrm{Al}}$ & $\mathrm{Co}$ & $\mathrm{Cr}$ & $\mathrm{Fe}$ & $\mathrm{Ni}$ \\
\hline \multirow[t]{3}{*}{ Figure $8 b(\mathrm{SEM})$} & 1 & 8.1 & 31.8 & 14.4 & 39.9 & 5.8 \\
\hline & 2 & 6.7 & 12.6 & 58.3 & 20.4 & 2.0 \\
\hline & 3 & 4.1 & 18.6 & 51.4 & 22.7 & 3.2 \\
\hline \multirow[t]{3}{*}{ Figure 11a (TEM) } & 1 & 0.9 & 53.2 & 4.5 & 27.6 & 13.8 \\
\hline & 2 & 7.2 & 34.1 & 15.3 & 37.6 & 5.8 \\
\hline & 3 & 1.5 & 0.1 & 84.4 & 13.6 & 0.4 \\
\hline
\end{tabular}

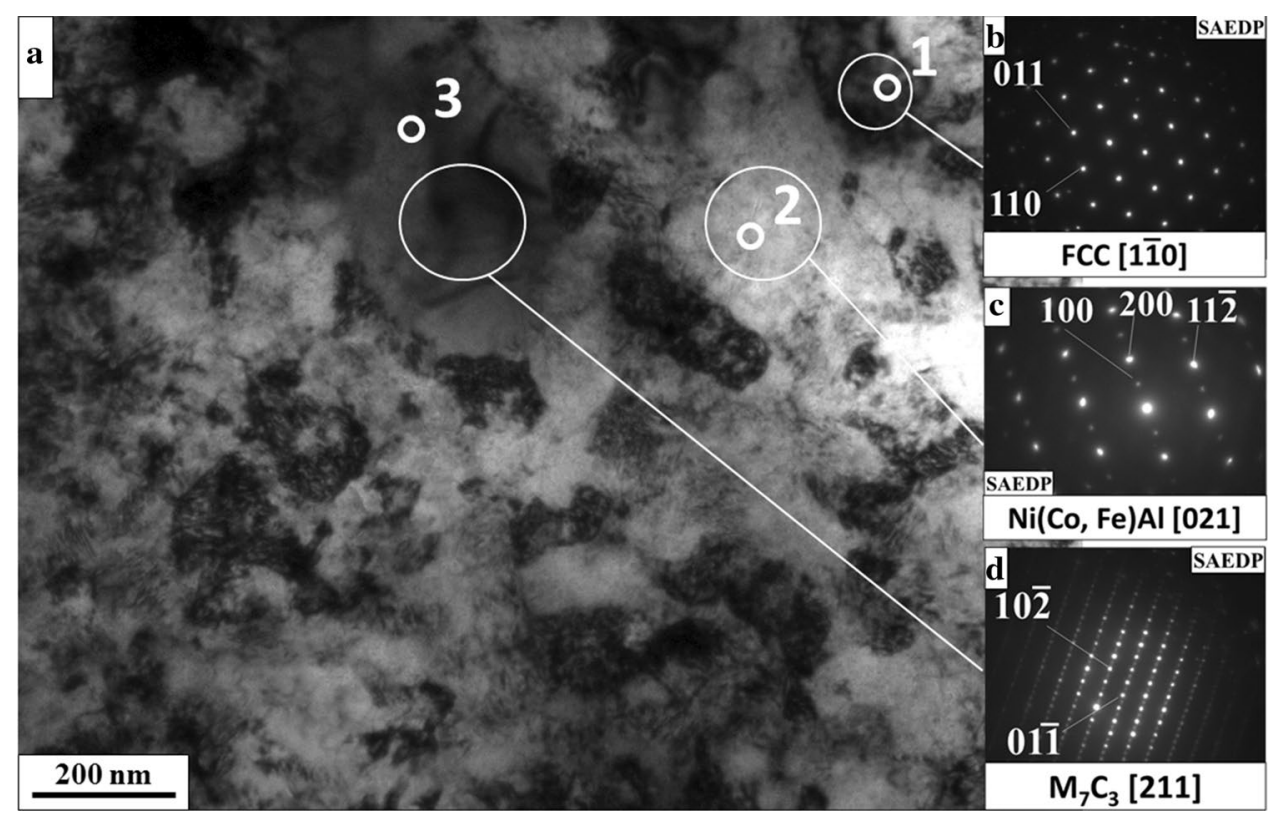



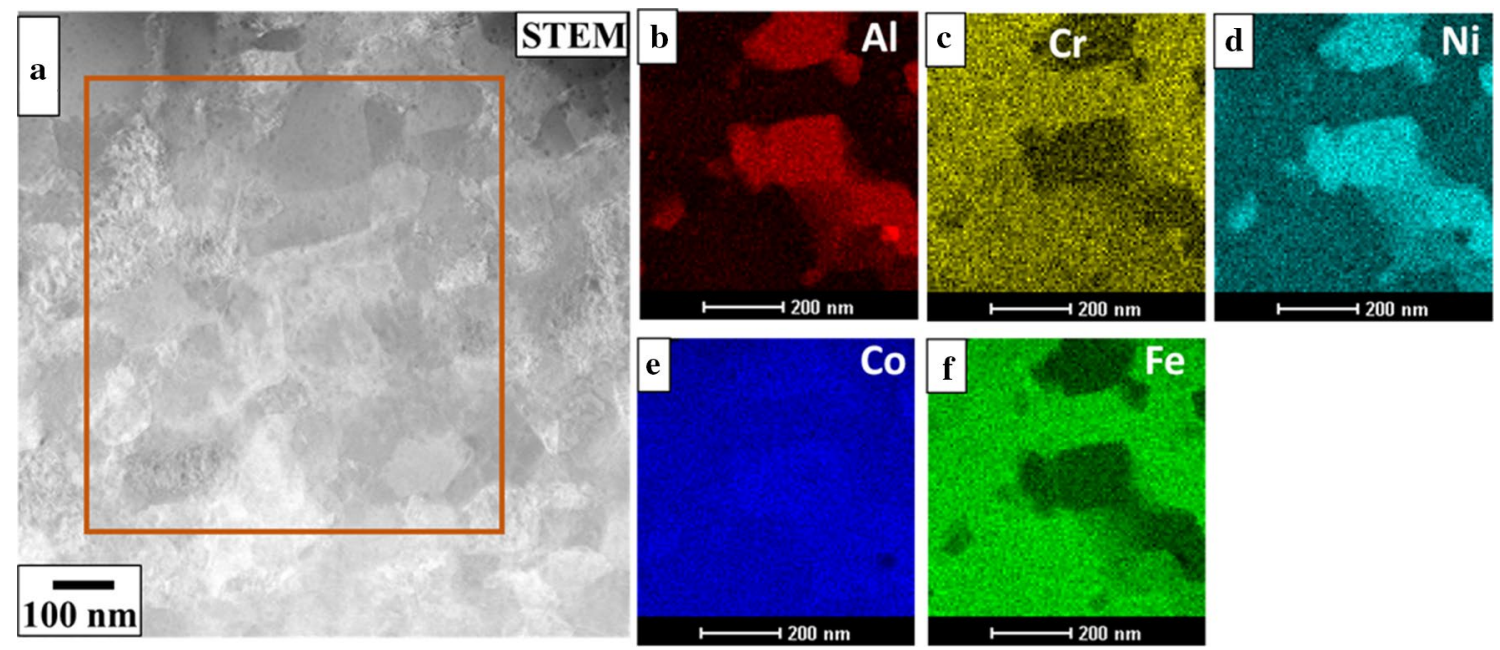

ents: b $\mathrm{Al} ; \mathbf{c} \mathrm{Cr} ; \mathbf{d ~ N i}$; e $\mathrm{Co} ; \mathbf{f} \mathrm{Fe}$

(a) The tendency for segregation of $\mathrm{Cr}$-enriched phases was already observed in the powder after mechanical synthesis (results not presented here refer to the fourelement alloy). It can be concluded that, depending on the $\mathrm{Cr}$ concentration, carbides (high $\mathrm{Cr}$ ), $\sigma$-phase (lower $\mathrm{Cr}$ ) or $\mathrm{Cr}$-enriched phases were formed during sintering. In TEM studies of the sintered base alloys, some oxides of $\mathrm{Cr}$ and $\mathrm{Al}$ were observed, which was difficult to avoid during mechanical alloying. Nevertheless, such oxide particles have often been observed even in arc-melted CoCrFeMnNi, CoCrFeNi as well as mechanical alloyed HEAs [57-63]. They can also make the mechanical synthesis process difficult, obstructing $\mathrm{Cr}$ from entering into the compounds.

(b) Apart from the volume fraction of the phases, their chemical composition is also important. TEM-EDS studies (due to the accuracy of measurement) of the FCC phases which control ductility were taken into account during the analysis. The concentration of $\mathrm{Ni}$ in the FCC solid solution depends on the Al content, which has a strong affinity to $\mathrm{Ni}$. In a 5-element equiatomic alloy, its content in the FCC phase reached up to about 13 at\% (Table 3, 3rd and 4th rows). However, when in non-equiatomic alloys, the overall $\mathrm{Ni}$ content decreased to $5 \%$, its concentration in the FCC solid solution was dependent on $\mathrm{Al}$ (Table 5, 4th row), and when its overall amount decreased, the content of $\mathrm{Ni}$ in the FCC solid solution increased (Table 6, 1st row).

\subsection{Mechanical Property Analysis}

A room temperature compression test was carried out to determine the deformation behavior. The stress-strain plots of $\mathrm{A} 125 \mathrm{Co} 25 \mathrm{Cr} 25 \mathrm{Fe} 25$ (dashed-double dotted curve),
A120Co20Cr20Fe20Ni20 (dashed-dotted one), Al10Co$30 \mathrm{Cr} 20 \mathrm{Fe} 35 \mathrm{Ni} 5$ (solid curve) and Al15Co30Cr15Fe40Ni5 (dashed) are presented in Fig. 13. To make the comparison easier, the mechanical properties have been listed in Table 7. For the four-element $\mathrm{A} 125 \mathrm{Co} 25 \mathrm{Cr} 25 \mathrm{Fe} 25 \mathrm{HEA}$, the compression strength $(\mathrm{CS})$ reached the maximum value of $3920 \mathrm{MPa}$, accompanied by the yield strength (YS) of $3500 \mathrm{MPa}$ and strain of $0.7 \%$. The average hardness of the as-cast sample was $990 \pm 45 \mathrm{HV}$. Its high value was connected with the presence of a BCC structure, which is characterized by a relatively high value of hardness and low ductility at room temperature, due to a small number of slip systems [59]. This is consistent with the SEM-SE analysis of the sample after compression (Fig. 14a), where the brittle fracture surface is visible. Other factors responsible for the increased CS and YS could be due to the character of the mechanical synthesis process, which introduced a high number of defects and strains to the microstructure [61]. Additionally, the high number of elements led to a decrease in stacking fault energy, which elevates the amount of dislocations and, consequently, blocks their movements and strengthens the material.

Praveen et al. [37] obtained a hardness of $1050 \mathrm{HV}$ in the same alloy, consolidated using SPS, however, they applied different milling and sintering conditions, which could have resulted in higher hardness. It should be noted that the value of CS obtained in the present study is one of the highest values listed in the literature on HEAs and is similar to WC-Co systems [69]. This is due to a unique microstructure, which consists of a mixture of nanometer grains of the BCC solid solution, $\mathrm{Cr}$ supersaturated in $\mathrm{Fe}$ and Ni particles and carbides.

The A120Co20Cr20Fe20Ni20 HEA revealed a yield strength of $2400 \mathrm{MPa}$ at the compression strength of 
Fig. 13 Compression curves of $\mathrm{A} 125 \mathrm{Co} 25 \mathrm{Cr} 25 \mathrm{Fe} 25$ (dasheddouble dotted curve), Al20Co$20 \mathrm{Cr} 20 \mathrm{Fe} 20 \mathrm{Ni} 20$ (dasheddotted), Al10Co30Cr20Fe35Ni5 (solid), Al15Co30Cr15Fe40Ni5 (dashed curve)

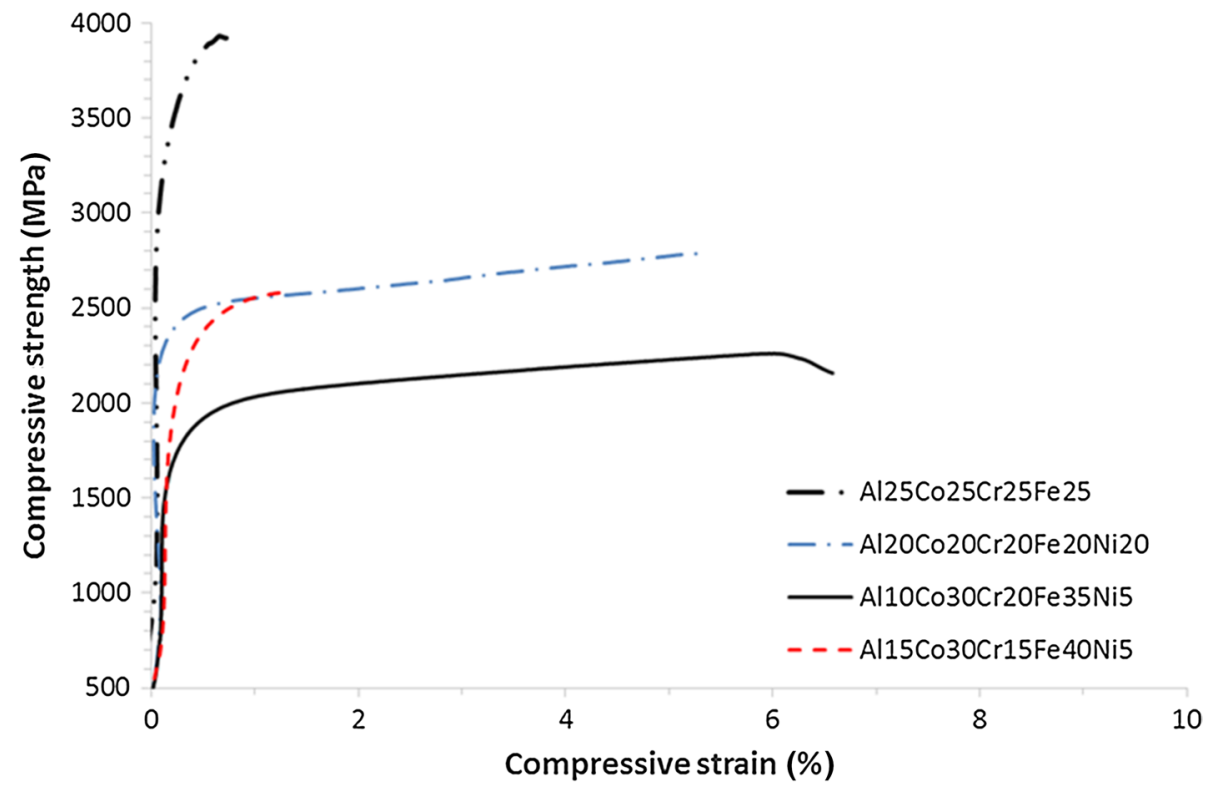

Table 7 Summary of the compression strength and hardness results of the studied samples

\begin{tabular}{lllll}
\hline HEA sample & UCS (MPa) & YS (MPa) & $\mathrm{a}_{\mathrm{C}}(\%)$ & Hardness (HV) \\
\hline A125Co25Cr25Fe25 & 3920 & 3500 & 0.7 & $990 \pm 45$ \\
A120Cr20Co20Fe20Ni20 & 2780 & 2400 & 5.2 & $710 \pm 15$ \\
Al10Co30Cr20Fe35Ni5 & 2230 & 1890 & 6.3 & $516 \pm 8$ \\
Al15Co30Cr15Fe40Ni5 & 2550 & 2190 & 1 & $697 \pm 15$ \\
\hline
\end{tabular}

$2780 \mathrm{MPa}$ and plastic strain of 5.2\% (Fig. 13; Table 7). The material had the hardness of $710 \mathrm{HV} \pm 15$. The lower strength (CS and YS) and higher plasticity (compressive strain) in comparison with the four-element system are connected with the presence of $\mathrm{Ni}$, which stabilizes the FCC solid solution structure. The concentration of the face-centered cubic structure in relation to the volume of BCC, as well as the strain hardening effect (applies mainly to FCC) are key factors influencing the mechanical properties [41]. It can be assumed that a high YS is due to the presence of the body-centered cubic structure, while the ductility is due to the FCC structure. Figure 14b shows a SEM micrograph of the ductile-brittle fracture surface of the sample. In comparison with the results included in [13], where the authors studied the same alloy obtained using MA, the sample in the present work revealed higher CS, YS and ductility, which could be connected with the different conditions of material preparation (higher milling time-60 h, and balls to powder ratio of 15:1), as well as additional powder annealing prior to sintering and a lower temperature of consolidation. This led to structure coarsening (which resulted from the Hall-Petch dependence)-lower mechanical properties, as well as a higher volume of FCC structure (which would be formed due to the presence of $\mathrm{C}$, coming from the PCA agent).
The as-cast Al20Co20Cr20Fe20Ni20 HEAs [64] had a single BCC structure and high CS of $3.5 \mathrm{GPa}$ at a plastic strain of about $6 \%$. It is well known that the cast structure possesses lower concentrations of defects, like porosity and oxides, in comparison with SPS-ed powder, which can decrease cracking. It should be noted that the strain hardening effect, determined based on the angle of the slope of the curve above $\mathrm{Rc}_{0.2}$, obtained in the compression test, had a very low value $\left(\approx 5^{\circ}\right)$ in comparison with the same alloy obtained by casting $\left(\approx 46^{\circ}\right)$. The differences between the two material states were the result of grain size (which was smaller in the sintered sample) and inhomogeneity of the composition. Segregation of the elements and the formation of various FCC solid solutions achieved in the SPSed sample were the main reasons for the limited hardening effect. This influenced the mechanical stability of the FCC phase and its susceptibility to transform into martensite [50, 64]. For example, in austenitic steels the $\gamma-\varepsilon$ transformation occurs in the presence of a large stress, which leads to the formation of a large number of defects, such as dislocations and stacking faults in the deformed austenite, leading to strengthening of the material during deformation [58, 65-69]. The mechanism of deformation, accompanied by the martensite formation observed in the stainless steel, has also been reported in Hadfield steel, a high-Ni alloy and 

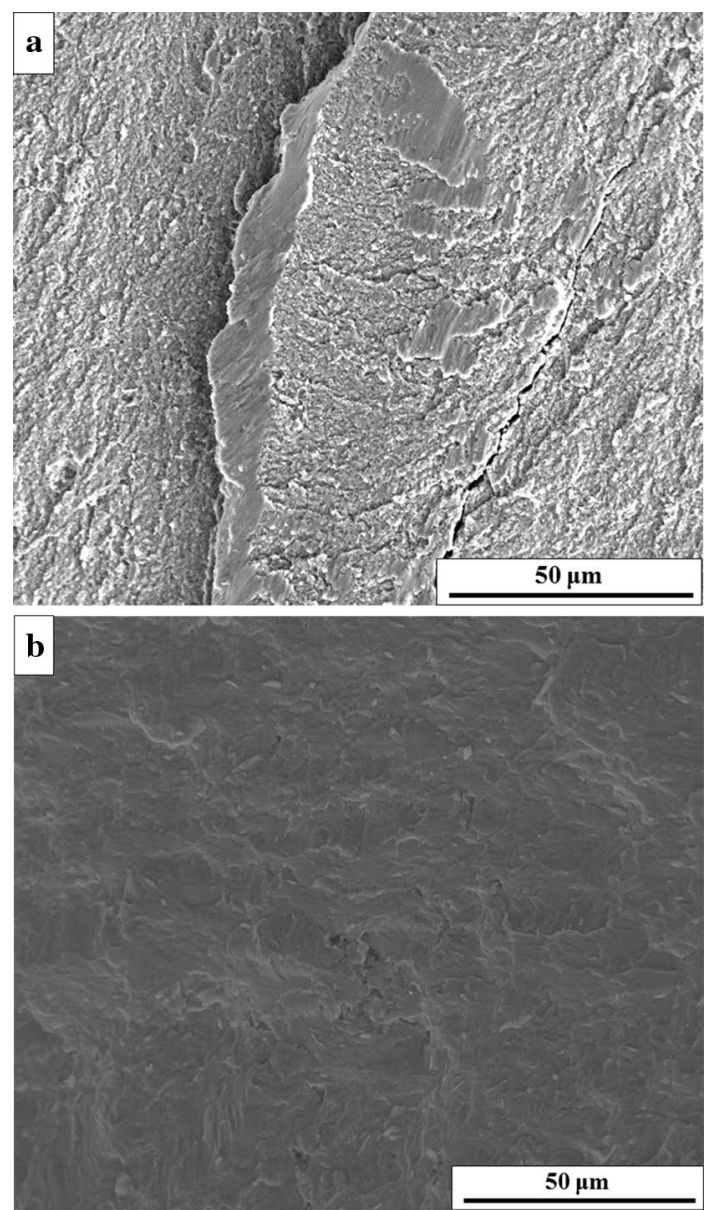

Fig. 14 SEM-SE micrographs shows an image of the brittle-ductile fracture surface of a $\mathrm{A} 125 \mathrm{Co} 25 \mathrm{Cr} 25 \mathrm{Fe} 25$, b A120Co20Cr20Fe20Ni20 HEA

TRIP steel [15]. Nevertheless, a very weak hardening effect was visible in the present work, which could be connected with a decrease in the concentration of $\mathrm{Cr}$ (in comparison with the same alloy in the as-cast state, in which hardening was significant).

The new five-element non-equiatomic high entropy alloys were designed in such a way as to obtain the content of FCC and BCC solid solutions in two different ranges (Table 1). The Al10Co30Cr20Fe35Ni5 HEA revealed the yield strength (YS) of $1890 \mathrm{MPa}$ at the compression strength of $2230 \mathrm{MPa}$ and plasticity $6.3 \%$ (Fig. 13; Table 7). The material had the hardness of $516 \mathrm{HV}$. In the Al15Co30Cr$15 \mathrm{Fe} 40 \mathrm{Ni} 5$ alloy, which was of a similar phase composition to the Al20Co20Cr20Fe20Ni20 HEA, the obtained yield strength was $2190 \mathrm{MPa}$ at the compression strength of $2550 \mathrm{MPa}$ and plastic strain 1\% (Fig. 13; Table 7). It was assumed that, in the volume of all the samples (four- and five-elements), the $\sigma$-phase and carbides were on the level below $3 \mathrm{vol} \%$ and that they had a similar effect on the material properties.
It should be noted that, with even small differences in the ratio of $\mathrm{FCC}$ and $\mathrm{BCC}(14 \mathrm{vol} \%)$ in the $\mathrm{Al} 10 \mathrm{Co} 30 \mathrm{Cr}$ 20Fe35Ni5 HEA and Al20Co20Cr20Fe20Ni20 HEA, the mechanical properties of the two compounds were different due to various chemical compositions of phases. For example, in the equiatomic system, the presence of $24 \mathrm{vol} \%$ of the FCC phase allowed ductility of about $5.2 \%$ to be obtained, while in the non-equiatomic HEA at the concentration of 37.9 vol $\%$ of FCC, the compressive strain was only $1 \%$. This was directly connected with the FCC structure mechanical stability, as well as with the behavior of BCC during compression, e.g. crack initiation and plasticity. Another factor which had an impact on the properties was the hardening effect induced by lattice distortion. Aluminum has the highest atomic radius and it can be seen that its content decreases with the yield strength drop. Additionally, aluminum can form hard and brittle intermetallic compounds, which could also be responsible for alloy strengthening [70].

These alloys have relatively high hardness and the highest ductility of all the other ones. It should also be taken into account that interstitial elements, e.g. $\mathrm{C}$ and $\mathrm{O}$, have influenced the mechanical properties of all the studied samples, which can be used to strengthen solid solutions. Nevertheless, the direct impact of this phenomena requires further complex studies.

The abrasion tests were carried out for all the studied high entropy alloys (Fig. 15; Table 8). To allow easy comparison of abrasion, the properties of the studied alloys are also depicted in the bar plot in Fig. 16. Carbide concentrations in all the samples were similar and it was assumed that differences in the FCC to BCC ratio, as well as various chemical compositions of solid solutions, have a significant influence on the abrasion coefficient (wear index) (Wv).

In the four-element $\mathrm{A} 125 \mathrm{Co} 25 \mathrm{Cr} 25 \mathrm{Fe} 25 \mathrm{HE}$ alloy, the abrasion coefficient was $11 \times 10^{-6} \mathrm{~mm}^{3} / \mathrm{Nm}$ (1st Table 8 ). Light microscopy analysis of the wear track showed bright areas, which could suggest the worn material being torn out (marked by arrows in Fig. 15a). There are also signs of abrasion by furrowing (Fig. 15a). The alloy had a two-phase structure, which consisted of Cr-enriched particles embedded in an Al-Co-Fe matrix. The softer phase was probably torn out and rubbed into the wear track. The cracks appeared and spread (propagated or developed) due to the multiple contact of the sample surface with the $\mathrm{Al}_{2} \mathrm{O}_{3}$ - ball and they resulted from material fatigue. Repeated contact loading during friction could lead to the removal of hard particles and the change of the 2-body into 3-body wear, and therefore to the acceleration of the wear process. The main factor for that could be the high strength of grain-matrix interfaces.

The presence of 20 at $\%$ nickel in the $\mathrm{Al} 20 \mathrm{Co} 20 \mathrm{Cr}$ $20 \mathrm{Fe} 20 \mathrm{Ni} 20$ alloy led to the highest value of $\mathrm{Wv}$, which was $241 \times 10^{-6} \mathrm{~mm}^{3} / \mathrm{Nm}$ (2nd row in Table 8). The microstructure taken from the wear track (Fig. 15b) confirmed the 
Fig. 15 Light microstructures showing wear tracks; a $\mathrm{A} 125 \mathrm{Co} 25 \mathrm{Cr} 25 \mathrm{Fe} 25$, b Al20Co20Cr20Fe20Ni20, c Al15Co30Cr15Fe40Ni5, d Al10Co30Cr20Fe35Ni5
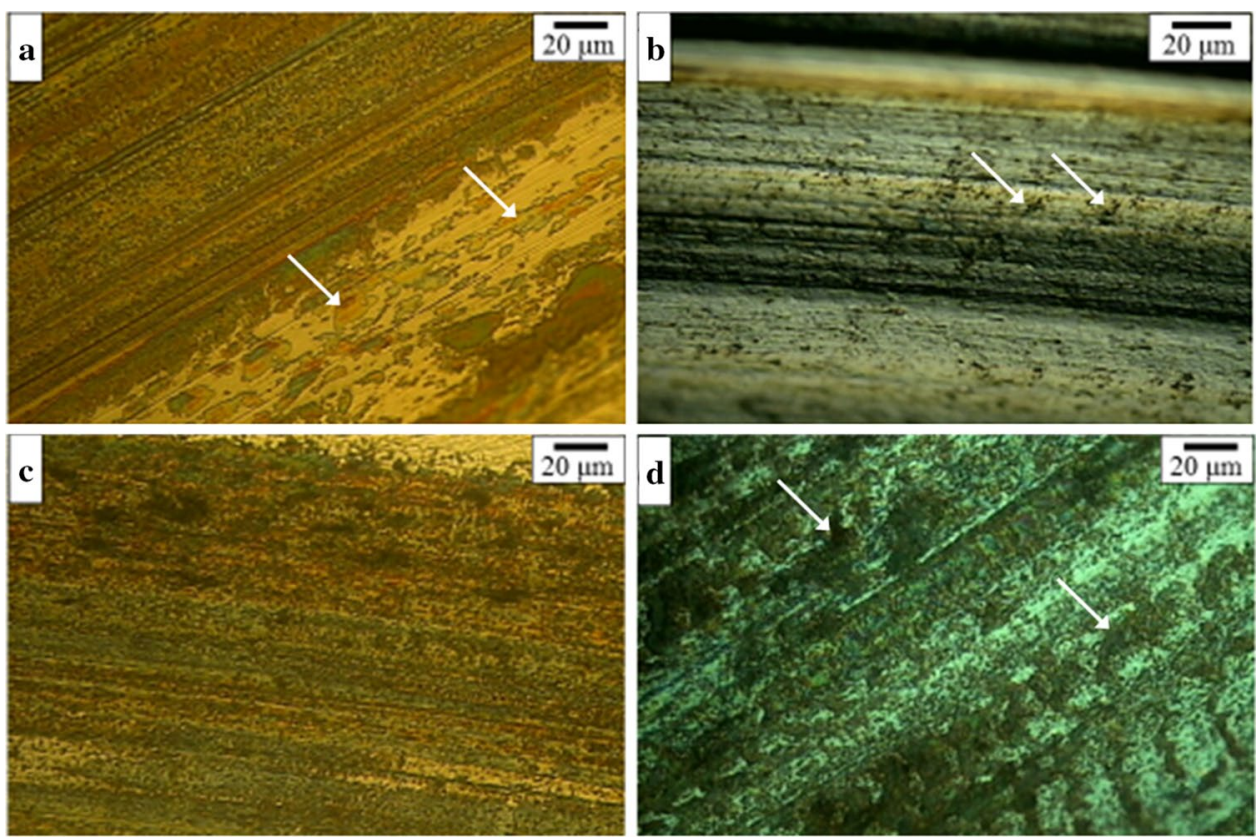

Table 8 Results of abrasion tests for the studied HE alloys

\begin{tabular}{lll}
\hline Sample & \multicolumn{2}{l}{$\begin{array}{l}\text { Abrasion coefficient, } \\
W_{v} \times 10^{-6}\left(\mathrm{~mm}^{3} / \mathrm{Nm}\right)\end{array}$} \\
\cline { 2 - 3 } & $W_{v}$ & $\begin{array}{l}\text { Standard } \\
\text { deviation }\end{array}$ \\
\hline A125Co25Cr25Fe25 & 11 & 0.3 \\
A120Co20Cr20Fe20Ni20 & 241 & 10 \\
A110Co30Cr20Fe35Ni5 & 3.6 & 1.1 \\
A115Co30Cr15Fe40Ni5 & 0.4 & 0.05 \\
\hline
\end{tabular}

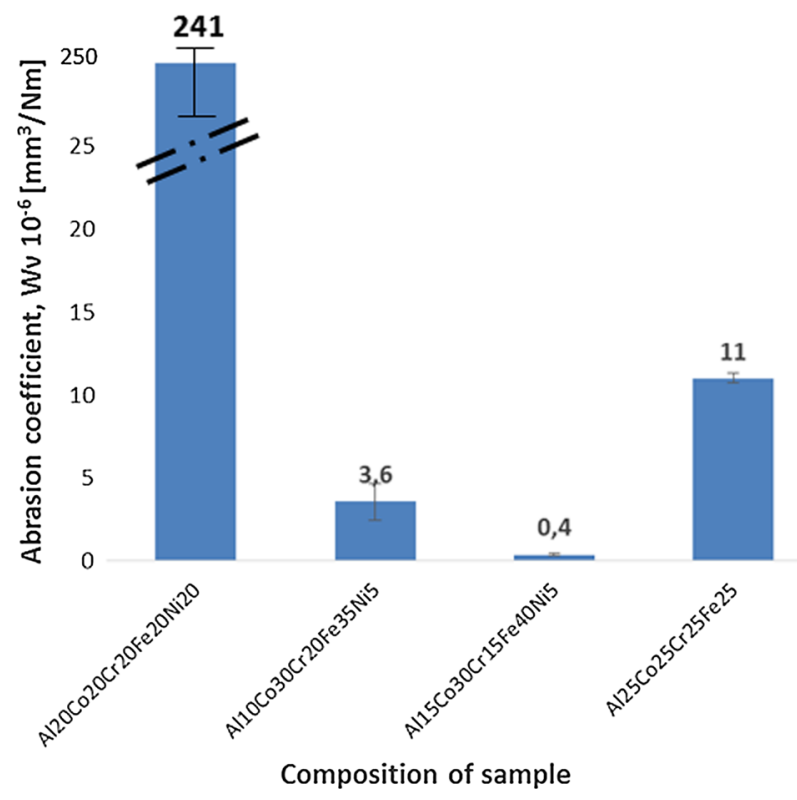

Fig. 16 Average value of the abrasion coefficient of HE alloys presence of the dominant mechanism of abrasive wearthere are visible furrows in the direction of friction and small micro cracks on the surface of the track (marked by arrows in Fig. 15b) due to the fatigue of the surface. This was probably caused by easy deformation of the FCC solid solution grains, which led to an increase in resistance to motion, resulting from the deformation and possible local superimposition of materials (transfer of worn material on the counter body and then high proneness to micro-welding as adhesive joints). Despite the lower hardness, the susceptibility to martensite formation at high stress concentrations of the Al20Co20Cr20Fe20Ni20 alloy (Table 8) might be a reason for a similar effect in $\mathrm{A} 125 \mathrm{Co} 25 \mathrm{Cr} 25 \mathrm{Fe} 25$, while lower hardness and higher deformation with a hard ball during friction caused more intensive wear. The FCC grains were deformed due to the presence of local stress, which was higher than the yield stress. This could have led to fractures on the surface due to fatigue.

In the case of high entropy alloys with non-equilibrium concentrations of elements, the tribological properties were very good. The Al15Co30Cr15Fe40Ni5 HE alloy had the lowest value of the abrasion coefficient $0.4 \times 10^{-6} \mathrm{~mm}^{3} /$ $\mathrm{Nm}$ (4th row in Table 8) - a microstructure typical of wear mechanisms was visible on the wear track (Fig. 15c). This material has high hardness $(697 \mathrm{HV})$ with very small ductility in the range of $1 \%$. Therefore, the tears and rubbing in of the material did not appear. In Al10Co30Cr20Fe35Ni5, which has the lowest hardness and plastic strain value of 6.3 , the abrasion coefficient was $3.6 \times 10^{-6} \mathrm{~mm}^{3} / \mathrm{Nm}$ (3rd row in Table 8). Analysis of the wear track (Fig. 15d) explicitly showed parts being torn out of the material (marked by arrow in Fig. 15d), which easily underwent plastic 
deformation due to its softness. There are also visible adhesive joints (micro-welds) and fine pits. At that stage, the samples additionally revealed the lowest hardness, which, according to Hertz theory, made them susceptible to plasticization. Metal hardness $(\mathrm{H})$ is proportional to yield strength $\left(\mathrm{R}_{\mathrm{e}}\right)$ which is given by

$\mathrm{R}_{\mathrm{e}}=1 / 3 \mathrm{H}$

It was assumed that, in the analyzed systems, a high volume of nickel had a negative effect on the tribological properties. This can be connected with the increased mechanical stability of austenite, which did not transform into hard martensite. Harder samples exhibited higher wear resistance.

\section{Conclusions}

Four compositions of high entropy alloys based on $\mathrm{Al}-\mathrm{Co}-\mathrm{Cr}-\mathrm{Fe}$ and $\mathrm{Al}-\mathrm{Co}-\mathrm{Cr}-\mathrm{Fe}-\mathrm{Ni}$ systems were prepared using mechanical alloying and consolidated by spark plasma sintering at $1050{ }^{\circ} \mathrm{C}$ for 15 min under 35-bar axial pressure in an argon atmosphere.

(1) The microstructure of the $\mathrm{A} 125 \mathrm{Co} 25 \mathrm{Cr} 25 \mathrm{Fe} 25$ high entropy alloy, consisting of a matrix with a high concentration of $\mathrm{Al}, \mathrm{Co}$ and $\mathrm{Fe}$, in which $\mathrm{Cr}$-enriched spherical particles $(50-200 \mathrm{~nm})$ were embedded, revealed the body-centered cubic structure of both components. Additionally, a small amount of $\mathrm{M}_{23} \mathrm{C}_{6}$ carbides was identified. The sample has a compression strength of $3920 \mathrm{MPa}$ accompanied by an increased yield strength of $3500 \mathrm{MPa}$ at a low strain of $0.7 \%$. Studies of the tribological behavior revealed very good abrasion resistance.

(2) A significant amount of the BCC solid solution (73 vol\%) with a smaller concentration of the FCC structure (24 vol\%), as well as $\mathrm{M}_{23} \mathrm{C}_{6}$ carbides (below $3 \mathrm{vol} \%$ ) were present in the $\mathrm{Al} 20 \mathrm{Co} 20 \mathrm{Cr} 20 \mathrm{Fe} 20 \mathrm{Ni} 20$ HEA. The yield strength was $2400 \mathrm{MPa}$ at the compression strength of $2780 \mathrm{MPa}$ and ductility of $5.2 \%$. The material reached the hardness of $710 \mathrm{HV} \pm 15$ at $2780 \mathrm{MPa}$ and plastic strain of $5.2 \%$.

(3) The non-equiatomic Al10Co30Cr20Fe35Ni5 and A115Co30Cr15Fe40Ni5 HEA microstructures consisted of a mixture of AlNi-B2, Cr-enriched phase, FCC and BCC solid solutions, as well as the $\sigma$-phase. The complex structure of the studied samples was the result of changeable mechanical properties. The presence of the FCC phase led to a decrease in strength to $2230 \mathrm{MPa}$ and hardness $516 \mathrm{HV}$, at the expense of plasticity reaching $6.3 \%$ in the new high entropy Al10Co$30 \mathrm{Cr} 20 \mathrm{Fe} 35 \mathrm{Ni} 5$ alloy. Al15Co30Cr15Fe40Ni5 had the highest wear resistance.
Acknowledgements The research was supported by the Polish Iuventus Plus program, entitled "Effect of $\mathrm{Al}_{2} \mathrm{O}_{3}$ and $\mathrm{SiC}$ nanoparticles on the microstructure and mechanical properties of FeNiCoCrMn and AlCoCrFeNi high entropy alloys, No. 0400/IP2/2015/73”.

Open Access This article is distributed under the terms of the Creative Commons Attribution 4.0 International License (http://creativeco mmons.org/licenses/by/4.0/), which permits unrestricted use, distribution, and reproduction in any medium, provided you give appropriate credit to the original author(s) and the source, provide a link to the Creative Commons license, and indicate if changes were made.

\section{References}

1. J.W. Yeh, S.K. Chen, S.J. Lin, J.Y. Gan, T.S. Chin, T.T. Shun, C.H. Tsau, S.Y. Chang, Adv. Eng. Mater. 6, 299 (2004)

2. B. Cantor, I.T.H. Chang, P. Knight, A.J.B. Vincent, Mater. Sci. Eng. A 375, 213 (2004)

3. L. Rogal, F. Czerwinski, P.T. Jochym, L. Litynska-Dobrzynska, Mater. Des. 92, 8 (2016)

4. L. Rogal, P. Bobrowski, F. Körmann, S. Divinski, F. Stein, B. Grabowski, Sci. Rep. 7, 2209 (2017)

5. L. Rogal, J. Morgiel, Z. Światek, F. Czerwiński, Mater. Sci. Eng. A 651, 590 (2016)

6. Ł. Rogal, D. Kalita, A. Tarasek, P. Bobrowski, F. Czerwinski, J. Alloys Compd. 708, 344 (2017)

7. Ł. Rogal, D. Kalita, L. Litynska-Dobrzynska, Intermetallics 86, 104 (2017)

8. F.J. Wang, Y. Zhang, G.L. Chen, H.A. Davies, J. Eng. Mater. Technol. 131, 34 (2009)

9. Ł. Rogal, Mater. Des. 119, 406 (2017)

10. J.Y. He, C. Zhu, D.Q. Zhou, W.H. Liu, T.G. Nieh, Z.P. Lu, Intermetallics 55, 9 (2014)

11. N. Stepanov, M. Tikhonovsky, N. Yurchenko, D. Zyabkin, M. Klimova, S. Zherebtsov, A. Efimov, G. Salishchev, Intermetallics 59, 8 (2015)

12. Z. Wu, C.M. Parich, H. Bei, J. Alloys Compd. 647, 815 (2015)

13. W. Ji, Z. Fu, W. Wang, H. Wang, J. Zhang, Y. Wang, F. Zhang, J. Alloys Compd. 589, 61 (2014)

14. Y.P. Wang, B.S. Li, M.X. Ren, C. Yang, H.Z. Fu, Mater. Sci. Eng. A 491, 154 (2008)

15. V. Tsakiris, D.V. Edmonds, Mater. Sci. Eng. A 273, 430 (1999)

16. J.W. Yeh, Ann. Chim. Sci. Mat. 31, 633 (2006)

17. S. Mohanty, T.N. Maity, S. Mukhopadhyay, S. Sarkar, N.P. Gurao, S. Bhowmick, K. Biswas, Mater. Sci. Eng. A 679, 299 (2017)

18. Z. Tang, O.N. Senkov, C.M. Parish, C. Zhang, F. Zhang, L.J. Santodonato, G. Wang, G. Zhao, F. Yang, P.K. Liaw, Mater. Sci. Eng. A 647, 299 (2015)

19. W.D. Callister, Fundamentals of Materials Science and Engineering, 2nd edn. (Wiley, New York, 2005), p. 252

20. Z. Li, K.G. Pradeep, Y. Deng, D. Raabe, C.C. Tasan, Nature 534, 227 (2016)

21. I.S. Wani, T. Bhattacharjee, S. Sheikh, P.P. Bhattacharjee, S. Guo, N. Tsuji, Mater. Sci. Eng. A 675, 99 (2016)

22. M. Feuerbacher, Sci. Rep. 6, 29700 (2016)

23. Q. Wang, Y. Ma, B. Jiang, X. Li, Y. Shi, C. Dong, P.K. Liaw, Scr. Mater. 120, 85 (2016)

24. W.R. Wang, W.L. Wang, S.C. Wang, Y.C. Tsai, C.H. Lai, J.W. Yeh, Intermetallics 26, 44 (2012)

25. S.G. Ma, Y. Zhang, Mater. Sci. Eng. A 532, 480 (2012)

26. J.M. Zhu, H.M. Fu, H.F. Zhang, A.M. Wang, H. Li, Z.Q. Hu, Mater. Sci. Eng. A 527, 7210 (2010) 
27. J.M. Zhu, H.F. Zhang, H.M. Fu, A.M. Wang, H. Li, Z.Q. Hu, J. Alloys Compd. 497, 52 (2010)

28. H. Prasad, S. Singh, B.B. Panigrahi, J. Alloys Compd. 692, 720 (2017)

29. J.W. Yeh, S.K. Chen, S.J. Lin, J.Y. Gan, T.S. Chin, T.T. Shun, C.H. Tsau, S.Y. Chang, Adv. Eng. Mater. 6(5), 299 (2004)

30. Y. Zhang, T.T. Zuo, Z. Tang, M.C. Gao, K.A. Dahmen, P.K. Liaw, Z.P. Lu, Prog. Mater. Sci. 61, 1 (2014)

31. C.P. Lee, C.C. Chang, Y.Y. Chen, J.W. Yeh, H.C. Shih, Corros. Sci. 50, 2053 (2008)

32. J.H. Shin, J.S. Jeong, J.W. Lee, Mater. Charact. 99, 230 (2015)

33. K.Y. Tsai, M.H. Tsai, J.W. Yeh, Acta Mater. 61, 4887 (2013)

34. Y. Du, Y.A. Chang, B. Huang, W. Gong, Z. Jin, H. Xu, Z. Yuan, Y. Liu, Y. He, F.Y. Xie, Mater. Sci. Eng. A 363, 140 (2003)

35. T.B. Massalski, Binary Alloy Phase Diagrams, 2nd edn. (ASM International, Materials Park, 1990)

36. R. Raghavan, K.C. Hari Kumar, B.S. Murty, J. Alloys Compd. 544, 152 (2012)

37. S. Praveen, A. Anupam, T. Sirasani, B.S. Murty, R.S. Kottada, Trans. Indian Inst. Met. 66, 369 (2013)

38. H.K.D.H. Bhadeshia, Steel for bearings. Prog. Mater. Sci. 57, 268-435 (2012)

39. L.J. Wibberley, T.F. Wall, Fuel 61, 87 (1982)

40. E.A.A. Nilsson, Doctoral Thesis. Lulea University of Technology (2017)

41. B.S. Murty, J.W. Yeh, S. Ranganathan, High Entropy Alloys, 1st edn. (Butterworth-Heinemann, Oxford, 2014)

42. D. Raabe, C.C. Tasan, H. Springer, M. Bausch, Steel Res. Int. 86, 1127 (2015)

43. R. Schnitzer, R. Radis, M. Nöhrer, M. Schober, R. Hochfellner, S. Zinner, E. Povoden-Karadeniz, E. Kozeschnik, H. Leitner, Mater. Chem. Phys. 122, 138 (2010)

44. Z. Guo, W. Sha, D. Vaumousse, Acta Mater. 51, 101 (2003)

45. D.H. Ping, M. Ohnuma, Y. Hirakawa, Y. Kadoya, K. Hono, Mater. Sci. Eng. A 394, 285 (2005)

46. E.V. Pereloma, R.A. Stohr, M.K. Miller, S.P. Ringer, Metall. Mater. Trans. A 40, 3069 (2009)

47. M. Zajusz, J. Dąbrowa, M. Danielewski, Scr. Mater. 138, 48 (2017)

48. C. Zhang, F. Zhang, S. Chen, W. Cao, JOM 64(7), 839 (2012)

49. F. Zhang, C. Zhang, S.L. Chen, J. Zhu, W.S. Cao, U.R. Kattner, Calphad 45, 1 (2014)
50. Y. Zhang, Y.J. Zhou, J.P. Lin, G.L. Chen, P.K. Liaw, Adv. Eng. Mater. 10, 534 (2008)

51. X. Yang, Y. Zhang, Mater. Chem. Phys. 132, 233 (2012)

52. Y. Zhang, Z.P. Lu, S.G. Ma, P.K. Liaw, Z. Tang, Y.Q. Cheng, M.C. Gao, MRS Commun. 4, 57 (2014)

53. S. Guo, C. Ng, J. Lu, C.T. Liu, J. Appl. Phys. 109(10), 103 (2011)

54. Z. Li, S. Zhao, H. Diao, P.K. Liaw, M.A. Meyers, Sci. Rep. 7, 42742 (2017)

55. Y. Kawamura, K. Hayashi, A. Inoue, T. Masumoto, Mater. Trans. 42, $1172(2001)$

56. A. Inoue, Y. Kawamura, M. Matsushita, K. Hayashi, J. Koike, J. Mater. Res. 16, 1894 (2001)

57. J. Dutkiewicz, Ł. Rogal, M. Szutkowska, W. Leśniewski, P. Dłużewski, P. Bobrowski, 10th International Conference on the Physical Properties and Application of Advanced Materials (ICPMAT2015) (Chiang Mai, 2015)

58. T. Suzuki, H. Kojima, K. Suzuki, T. Hashimoto, M. Ichihara, Acta Metall. 25, 1151 (1977)

59. Q. Wei, S. Cheng, K.T. Ramesh, E. Ma, Mater. Sci. Eng. A 381, 71 (2004)

60. R. Sriharitha, B.S. Murty, R.S. Kottada, Intermetallics 32, 119 (2013)

61. G. Straffelini, J. Powder Metall. 48, 189 (2005)

62. O.A. Waseem, H.-J. Ryu, Sci. Rep. 7, 1926 (2017)

63. S. Praveen, J. Basu, S. Kashyap, R.S. Kottada, J. Alloys Compd. 662, 361 (2016)

64. Y. Zhang, S.G. Ma, J.W. Qiao, Metall. Mater. Trans. A 43, 2625 (2012)

65. J.W. Brooks, M.H. Loretto, R.E. Smallman, Acta Metall. 27, 1829 (1979)

66. A. Das, P.C. Chakraborti, S. Tarafder, H.K.D.H. Bhadeshia, Mater. Sci. Technol. 27, 366 (2011)

67. J. Dutkiewicz, G. Kostorz, Mater. Sci. Eng. A 132, 267 (1991)

68. Ł. Rogal, J. Dutkiewicz, Mater. Sci. Eng. A 603, 93 (2014)

69. Ł. Rogal, J. Dutkiewicz, T. Czeppe, J. Bonarski, B. OlszowskaSobieraj, Trans. Nonferrous Met. Soc. China 20, 1033 (2010)

70. T.G. Gray, T.M. Pollock, Strain hardening, in Intermetallic Compounds-Principles and Practice, vol. 3, ed. by J.H. Westbrook, R.L. Fleischer (Wiley, New York, 2002), pp. 361-379 